\title{
Multi-objective optimization of the flush-type intake duct for a waterjet propulsion system
}

\author{
Renfang Huang ${ }^{\mathrm{a}}$, Yuanxing Dai ${ }^{\mathrm{b}}$, Xianwu Luo ${ }^{\mathrm{c}, *}$, Yiwei Wang ${ }^{\mathrm{a},{ }^{, * *}}$, Chenguang Huang ${ }^{\mathrm{a}}$ \\ ${ }^{a}$ Key Laboratory for Mechanics in Fluid Solid Coupling Systems, Institute of Mechanics, Chinese Academy of Sciences, Beijing, 100190, China \\ ${ }^{\mathrm{b}}$ Science and Technology on Water Jet Propulsion Laboratory, Shanghai, 200011, China \\ ${ }^{\mathrm{c}}$ Department of Energy and Power Engineering, Tsinghua University, Beijing, 100084, China
}

\section{A R T I C L E I N F O}

\section{Keywords:}

Intake duct

Waterjet propulsion

Multi-objective optimization

\begin{abstract}
A B S T R A C T
The intake duct is an important component of waterjet propulsion system and its hydraulic performance is directly connected with the capability of the waterjet pump and even the propulsion performance of the system. In order to optimize the flush-type intake duct, the present paper proposes a multi-objective optimization system including Design of Experiments (DOE), Computational Fluid Dynamics (CFD), three-dimensional parametric design, approximate model, the modified Non-dominated Sorting Genetic Algorithm-II (NSGA-II) and a Technique for Ordering Preferences by Similarity to Ideal Solution (TOPSIS). The nonuniformity and perpendicularity of outflow, and hydraulic efficiency for the intake duct are treated as the optimization objectives with four geometrical parameters as the design variables. Local sensitivity analyses indicate that the optimization objectives are significantly affected by the inclination angle and slightly affected by the lip vertical distance of the intake duct. During IVR $=0.3-0.8$, the outflow quality and hydraulic efficiency of the optimized intake duct are greatly improved. The nonuniformity after optimization decreases by $27.8 \%$ and perpendicularity increases by $3.07 \%$ at the design condition of IVR $=0.7$ and $V_{\mathrm{s}}=19.49 \mathrm{~m} / \mathrm{s}$. Based on the flow at the outlet plane of intake duct, the pressure distribution after optimization is very uniform and the tangential velocity is small without obvious secondary flow. During the application to a mixed-flow waterjet propulsion system at various navigation speeds, the nonuniformity of the optimized intake duct decreases by $20.4 \%$ and perpendicularity increases by $4.11 \%$ on average, demonstrating that the optimized intake duct performs a better outflow quality. It is also noted that the non-uniform flow from the intake duct mainly affects pressure distribution on the suction surface of impeller blade and causes different shaft power.
\end{abstract}

\section{Introduction}

Waterjet propulsion is widely used in high-speed marine vessels over 30 knots with advantages of high propulsive efficiency, good maneuverability, less vibration and good anti-cavitation performance (Park et al., 2005b). The system includes the intake duct, the waterjet pump, the nozzle and the steering device. In the system, a waterjet pump is the main component to produce the jet at the nozzle exit with its hydraulic efficiency up to $90 \%$ by using the advanced modern design methods (Bulten, 2006), while the intake duct provides the waterjet pump with the water downstream the vessel hull. Thus, the outflow of intake duct will strongly affect the pump performance and even the propulsion capability of the system.
In the past, numerous experiments had been carried out to study the flow characteristics in the intake duct and analyze the effects of the nonuniform suction flows on the waterjet pump. Griffith-Jones (1994) conducted massive wind tunnel tests of a flush entry S-bend intake duct for the waterjet propulsion. His measurements showed that the streamtube cross-section was roughly semi-elliptical in shape and around $40 \%$ wider than the intake entrance, and the major flow feature observed in experiments is the roof separation zone which is dependent on Reynolds number and the ingested boundary layer thickness. Roberts (1998) thoroughly investigated the influence of hull boundary layers on typical waterjet propulsion ducts through experiments, and found that a thickened boundary layer causes more extensive flow separation with adverse effects on the performance of such ducts. Besides, the roof

\footnotetext{
* Corresponding author.

$* *$ Corresponding author.

E-mail addresses: luoxw@mail.tsinghua.edu.cn (X. Luo), wangyw@imech.ac.cn (Y. Wang).
} 


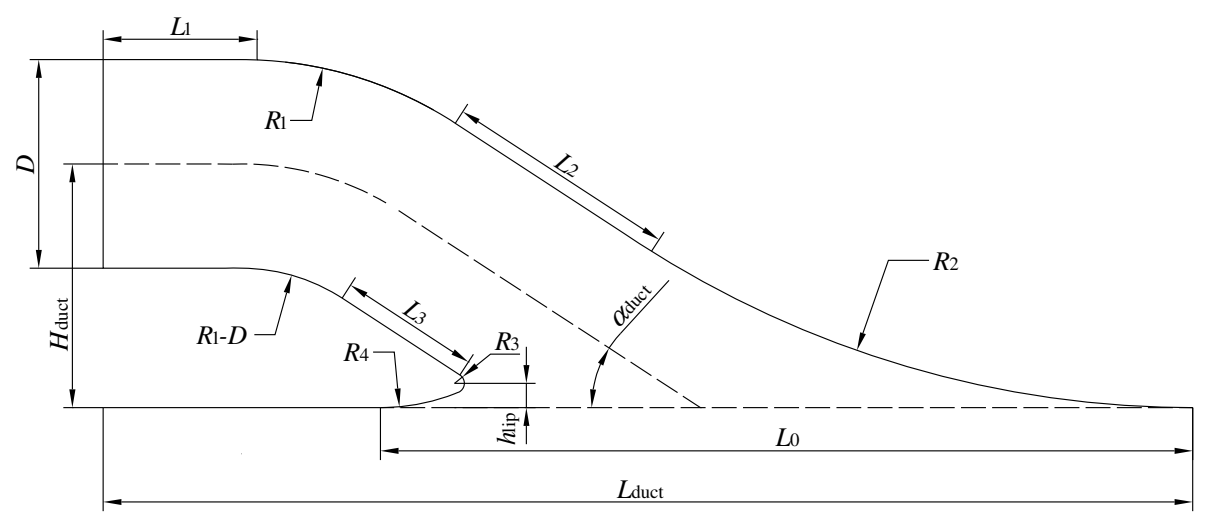

Fig. 1. Design parameter of an intake duct.

Table 1

Ranges for the host variables.

\begin{tabular}{ll}
\hline Variable & Range \\
\hline$\alpha_{\text {duct }}$ & $23.11-35.9$ \\
$h_{\text {lip }}$ & $19.75-53.45$ \\
$R_{2}$ & $878.4-1711.6$ \\
$R_{3}$ & $4.88-33.96$ \\
\hline
\end{tabular}

separation zone observed by Griffith-Jones (1994) is also clearly presented and the cut-water flow separation will choke the intake duct and severely suppress the available maneuvering thrust. With the development and improvement of the Computational Fluid Dynamics (CFD), numerical simulation of the internal flows is becoming an important tool in the duct research. Bulten (2006) numerically investigated the effects of non-uniform inflows on the waterjet propulsion performance. Instead of the general 1/7-th power law velocity profile for high ship speeds, an alternative velocity profile is proposed to produce a thicker boundary layer and it is validated by wind tunnel experiments (Bulten, 1999). Park et al. (2005c) numerically simulated flows inside a flush-type intake duct by solving three-dimensional incompressible Reynolds-averaged Navier-Stokes (RANS) equations on multi-blocked grid system and clearly depicted the flow separations on the lip and along the corner of the side wall. Subsequently, he thoroughly analyzed the flow features of the waterjet propulsion system including the recovery of axial flow through the stator, the tip vortex, and the device performance of thrust and torque (Park et al., 2005b). Three-dimensional velocity fields were

Table 2

Results of the mesh independence test.

\begin{tabular}{lllllllll}
\hline & Elements & $\eta_{\text {duct }}(\%)$ & $\xi$ & $\phi_{\mathrm{p}}\left[^{\circ}\right]$ & \multicolumn{3}{c}{ Relative error of (\%) } \\
\cline { 6 - 9 } & & & & & & $\eta_{\text {duct }}$ & $\xi$ & $\phi_{\mathrm{p}}$ \\
\hline case 1 & $1,735,737$ & 95.01 & 0.19 & 87.41 & 0.32 & 6.42 & 0.83 \\
case 2 & $2,263,814$ & 94.65 & 0.18 & 87.43 & 0.06 & 4.70 & 0.80 \\
case 3 & $3,318,744$ & 95.19 & 0.19 & 88.48 & 0.51 & 6.91 & 0.39 \\
case 4 & $3,746,845$ & 94.91 & 0.18 & 88.25 & 0.22 & 4.35 & 0.13 \\
case 5 & $10,023,306$ & 94.70 & 0.18 & 88.14 & 0 & 0 & 0 \\
\hline
\end{tabular}

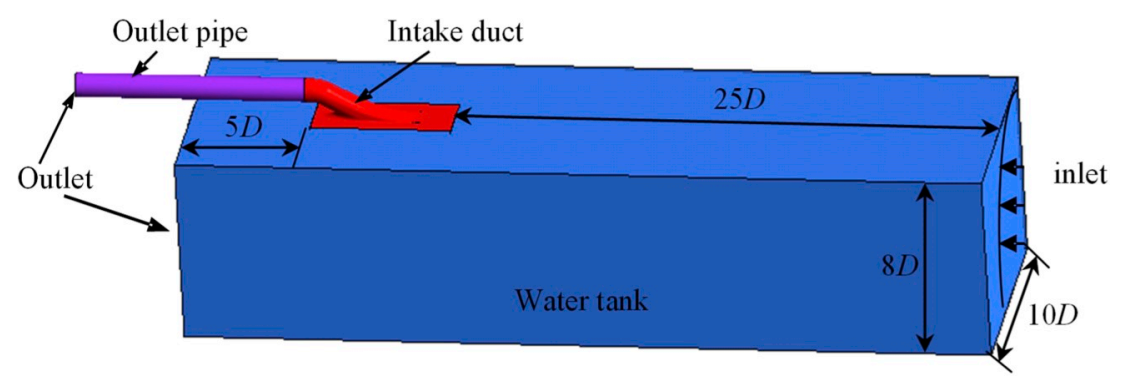

Fig. 2. Computational domain of the intake duct.

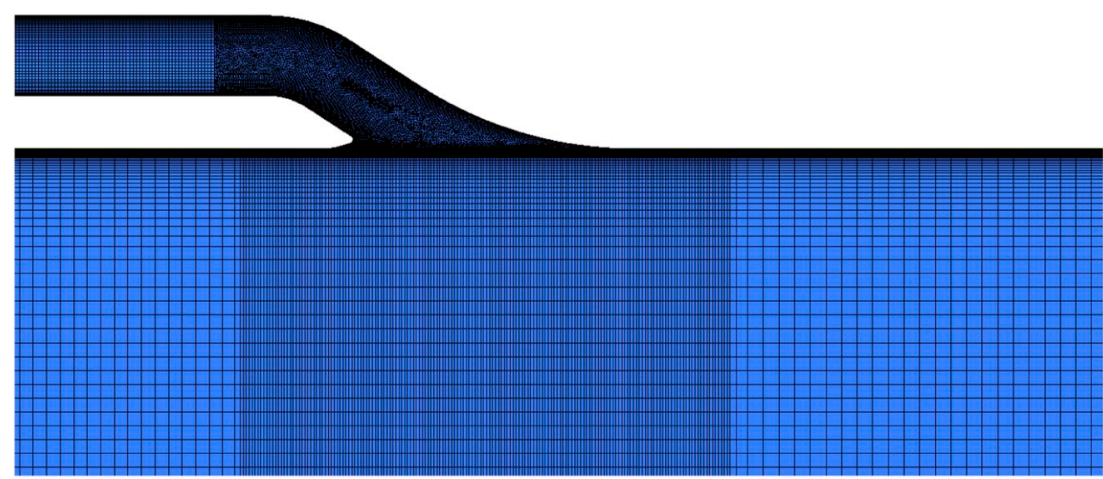

Fig. 3. Mesh distributions of case 4 . 


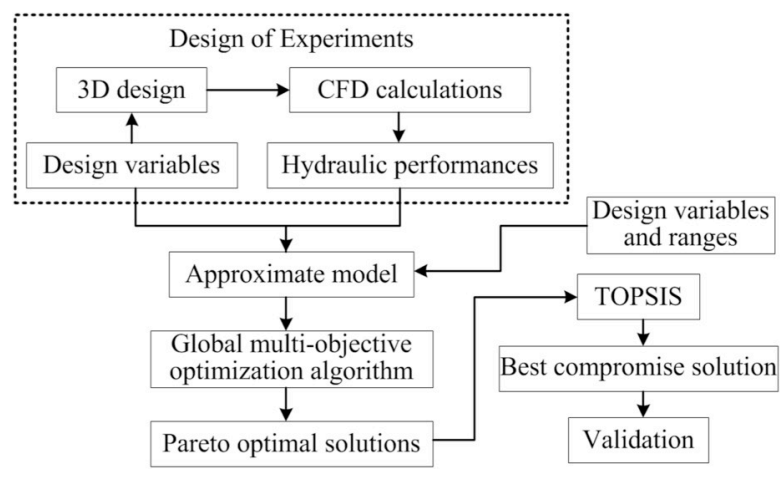

Fig. 4. Multi-objective optimization strategy for the intake duct.

\section{Table 3}

Parameter settings for the improved NSGA-II algorithm.

\begin{tabular}{ll}
\hline Parameter & Value \\
\hline Population & 200 \\
Generations & 200 \\
Crossover probability & 0.9 \\
Cross distribution index & 10 \\
Variation distribution index & 20 \\
\hline
\end{tabular}

successfully measured in a waterjet intake duct by using a stereoscopic PIV system, depicting that the flow is faster in the lip region than on the ramp side and a pair of counter-rotating vortices is observed at the nozzle exit due to the geometry variation from a rectangular to a circular section together with the sudden curvature variation on the lip (Jung et al., 2006). Van Esch (2009) experimentally investigated the hydrodynamics forces induced by the non-uniform suction flows in a mixed-flow waterjet pump by using a newly designed dynamometer which was equipped with six full Wheatstone bridges of strain gauges to measure the six generalized force components and placed between the pump shaft and the impeller with synchronously rotating with the rotor system. Measurement results showed that the non-uniform inflows do not affect the pump efficiency but will cause the reduction in the pump head, the torque together with the axial force, and a whirling motion of the rotor system along with a considerable steady radial force are clearly observed. Moreover, the non-uniform inflows can even cause the early onset cavitation, air ingestion and unsteady blade and shaft loads, resulting in excessive noise and vibration issues, which was found by Young et al. (2011) via fully coupled computational fluid dynamics simulations for a SES-waterjet pump operated on off-design conditions. This was also pointed out by numerical simulations of the non-uniform axial velocity entering the waterjet pump during a wide range of ship speeds corresponding to Froude numbers between 0.34 and 0.84 and Reynolds numbers between $3.6 \times 10^{8}$ and $9.0 \times 10^{8}$ (Duerr et al., 2013; Duerr and von Ellenrieder, 2015). Chang et al. (2010) investigated the effects of Inlet Velocity Ratio (IVR) conditions on the duct performance according to the outflow uniformity, cavitation, flow separation, flow energy loss and applicability to various operation conditions, and results revealed that the waterjet duct should be restricted at a certain extent of IVR $=0.6-0.8$ for good performance. Cao et al. (2017) analyzed the performance deviation between the uniform and non-uniform suction flows, and found that the large non-uniform suction flows would cause a substantial drop in the pump head with the primary feature of a distinct swirl distortion near the top evolving into a circumferential vortex.

Approximately $7-9 \%$ of the total power is lost in the intake duct (Park et al., 2005c; Verbeek, 1998) due to flow separations, nonuniformity, etc. In addition, the interaction between the ship and the waterjet propulsion device will affect the propulsion efficiency as much as $20 \%$ or more and this interaction mainly occurs near the intake duct (Ding and Wang, 2011; Terwisga and van, 1991). Thus, the optimization design of the intake duct with excellent performance is a key technology in the optimization design of a waterjet propulsion device. Based on above investigations, a good duct design should have characteristics of uniform outflows, few flow separations, good cavitation performance, small flow loss, etc., and this is a multi-objective problem. However, constraint conditions, like the wide navigation range and the narrow installation space, put forward higher requirements on the design of intake duct and it is difficult to meet these requirements using the traditional design method which is largely dependent on the design experiences. The well-known manufacturers of waterjet propulsion have developed the in-house code for the parametric design of the intake duct, while several investigations have been conducted to explain how a certain geometrical parameter affect intake duct performance. Wang et al. (2013) investigated the effects of the protecting grid on performances of intake duct and propulsion system, and found that the installation of inlet grids would reduce the inlet efficiency, non-uniformity and propulsion efficiency, and the recommended setting angle of the protecting grid is $5^{\circ}$ (Luo et al., 2015). Liu and Huang (2011) simulated the flow fields in a flush-type waterjet intake duct with various lips and comparatively analyzed the flow features including the head loss, the outflow quality, the pressure distribution. They suggested that the lip with a little more forward position and sharper shape is helpful to improve the hydrodynamic performance. Lv (2014) systematically conducted numerical simulations for various intake duct schemes by adjusting the inlet angle, the lip radius and shapes, the ramp radius and the intake shapes. Based on analyses of their efficiency, flow uniformity, velocity contours and the stagnation point positions, she finally obtained the best compromise design for the intake duct. Ji et al. (2016a) studied the relationship between the intake duct efficiency and the inclination angle through CFD technique, and results revealed that the intake duct efficiency would slightly decrease with the increase of the inclination angle, indicating that the inclination angle has little effect on the intake duct efficiency. Then he also investigated the effects of lip parameters on the non-uniformity and the position of the stagnation point for better guidance of choosing the lip dimensions ( $\mathrm{Ji}$ et al., 2016b). In order to improve hydrodynamic performance and reduce the design cost, a parametric design method was proposed by Ding and Wang (2011), where the intake duct was characterized by 11 geometrical variables, three-dimensional structure could be automatically built once the governing variables changed and CFD technique was used to synthetically evaluate the performance from aspects of the outflow uniformity, flow separations, cavitation capability, flow loss, etc.

Till now, many studies have provided a good understanding of flow characteristics inside the intake duct and its effects on the performance of the waterjet propulsion system. However, there has been little attention paid to the multi-objective parametric design method of the intake duct. The present paper will propose a multi-objective optimization strategy for the intake duct in Section 2, which is based on Design of Experiments (DOE), Computational Fluid Dynamics (CFD), threedimensional parametric design, approximate model, the modified Non-dominated Sorting Genetic Algorithm-II (NSGA-II) and a Technique for Ordering Preferences by Similarity to Ideal Solution (TOPSIS). A flush-type intake duct of a waterjet propulsion system is treated to improve hydraulic efficiency and the outflow quality. Section 3 describes comprehensive analyses between the original intake duct and the optimized intake duct with/without considering the downstream waterjet pump and nozzle. Conclusions are given in Section 4.

\section{Multi-objective optimization strategy}

\subsection{Parametric design for the intake duct}

The type of waterjet intake is typically classified into two types (Allison, 1993): ram (also called as pod or strut) and flush intake. Ram intake duct is used on hydrofoil crafts and flush intake duct is widely used on monohulls, planning crafts, and catamarans (Park et al., 2005a). 

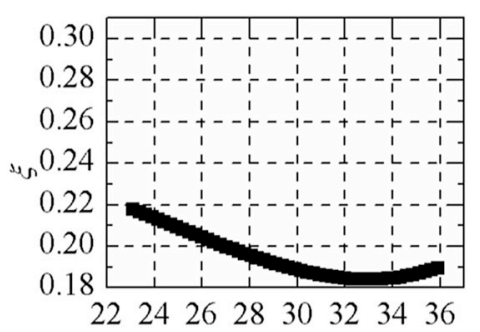

$\alpha_{\text {duct }}$
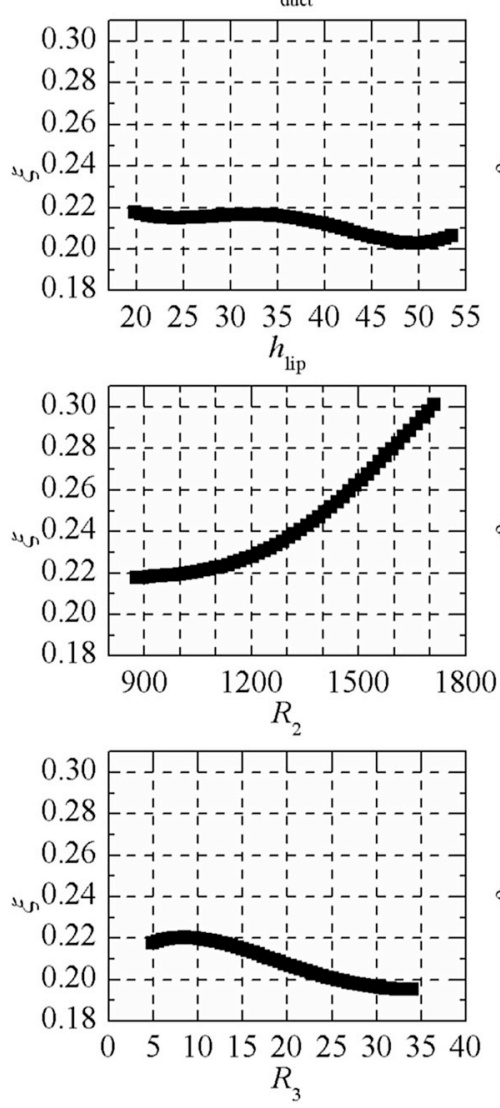

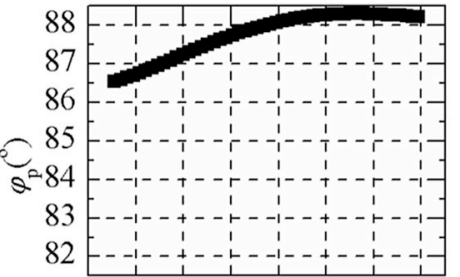

$22 \quad 24262830323436$ $\alpha_{\text {duct }}$

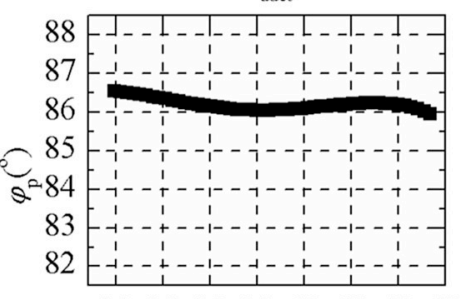

2025303540455055 $h_{\text {lip }}$
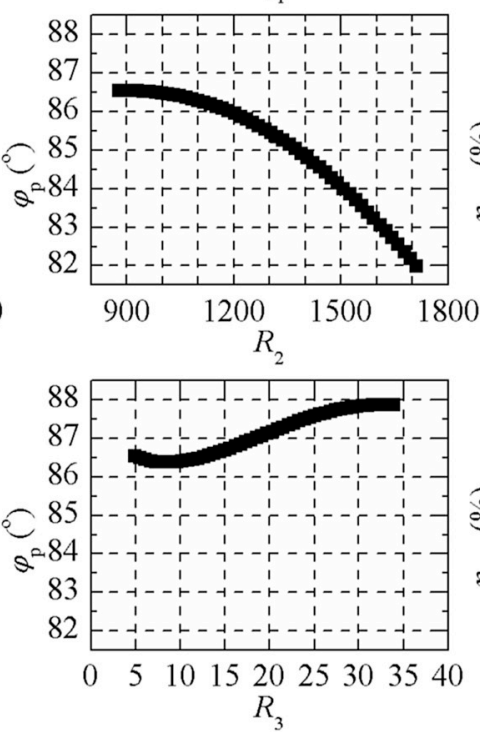

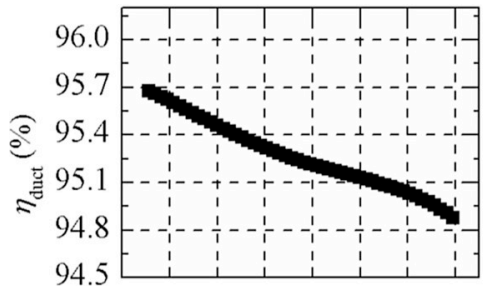

2224262830323436

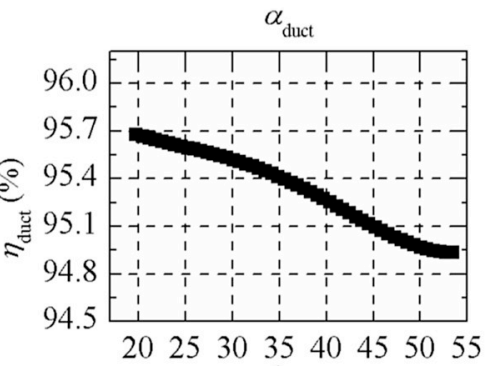

$20 \quad 25 \quad 30 \quad 35 \quad 40 \quad 45 \quad 50 \quad 55$ $h_{\text {lip }}$
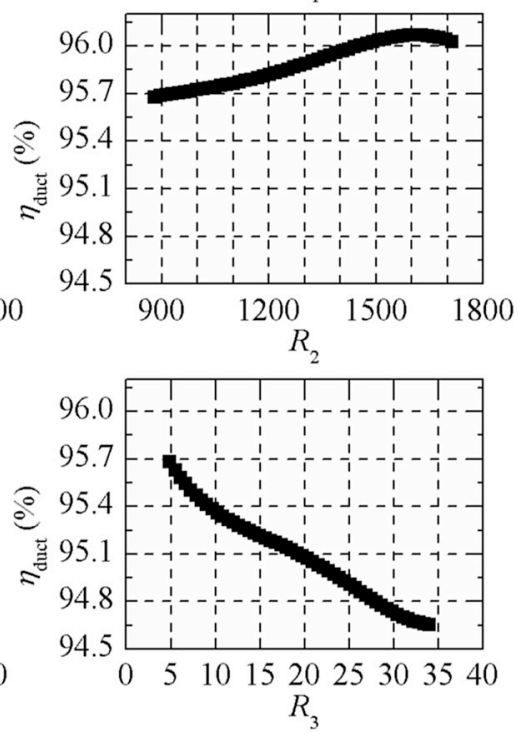

Fig. 5. Effects of design variables on each optimization objective.

Therefore, we take the flush-type intake duct as the optimization object due to its wide applicability and then develop a general multi-objective optimization strategy. This strategy not only can be used to optimize a flush-type intake duct but also can be used to optimize a duct for a specified waterjet pump.

The two-dimensional structure of the intake duct in a waterjet propulsion device is shown in Fig. 1, including the ramp section which is tangent to the ship hull, the inclined straight section, the elbow section and the horizontal straight section. Note that the hull may have a certain angle with the horizontal line according to the practical hull shape, herein the angle is $0^{\circ}$; and the elbow section is smoothly connected with the horizontal straight section and the inclined straight section by tangent arcs. Generally, the diameter $D$, the total length $L_{\text {duct }}$ and the mounting height $H_{\text {duct }}$ are subjected to the installation space in the marine vessels and the installation method of the waterjet propulsion device, so these three parameters are constant during our optimization design. As Fig. 1 shows, $L_{1}$ is the length of the horizontal straight section, $R_{1}$ is radius on the upper side of the elbow section, $L_{2}$ is the length on the upper side of the inclined straight section, $R_{2}$ is radius on the upper side of the ramp section, $L_{3}$ is the length on the lower side of the inclined straight section, $R_{3}$ and $R_{4}$ is the lip radius on the upper and lower side, respectively, $h_{\text {lip }}$ is the lip vertical distance from the center of the upper arc to the hull, $L_{0}$ is the inflow length, $\alpha_{\text {duct }}$ is the inclination angle between the axis of intake duct and the hull. Since all joins of the intake duct are connected by the tangent arcs, the geometric equations in the horizontal and vertical directions can be written in Eq. (1)-(4).

$L_{1}+R_{1} \bullet \sin \alpha_{\text {duct }}+L_{2} \bullet \cos \alpha_{\text {duct }}+R_{2} \bullet \sin \alpha_{\text {duct }}=L_{\text {duct }}$

$R_{1} \bullet\left(1-\cos \alpha_{\text {duct }}\right)+L_{2} \bullet \sin \alpha_{\text {duct }}+R_{2} \bullet\left(1-\cos \alpha_{\text {duct }}\right)=H_{\text {duct }}+\frac{D}{2}$

$\left(R_{1}-D\right) \bullet\left(1-\cos \alpha_{\text {duct }}\right)+L_{3} \bullet \sin \alpha_{\text {duct }}+R_{3} \bullet \cos \alpha_{\text {duct }}+h_{\text {lip }}=H_{\text {duct }}-\frac{D}{2}$

$$
\begin{aligned}
& \left(R_{4}-h_{\text {lip }}\right)^{2}+\left(L_{3} \bullet \cos \alpha_{\text {duct }}+\left(R_{1}-D-R_{3}\right) \bullet \sin \alpha_{\text {duct }}-\left(L_{\text {duct }}-L_{0}-L_{1}\right)\right)^{2} \\
& \quad=\left(R_{4}-R_{3}\right)^{2}
\end{aligned}
$$

The intake duct is characterized by 13 parameters including three constants $\left(D, L_{\text {duct }}\right.$ and $\left.H_{\text {duct }}\right)$ and ten variables. Based on the research conducted by Ji et al. (2016a), the straight lines have little impact on the hydrodynamic performance, so they are treated as dependent variables and calculated by Eq. (1)-(4), where $R_{1}=1.89 \mathrm{D}$ and $R_{4}=1.0 \mathrm{D}$. Therefore, the host variables are $\alpha_{\text {duct }}, h_{\text {lip }}, R_{2}, R_{3}$ with their ranges listed in Table 1 . 


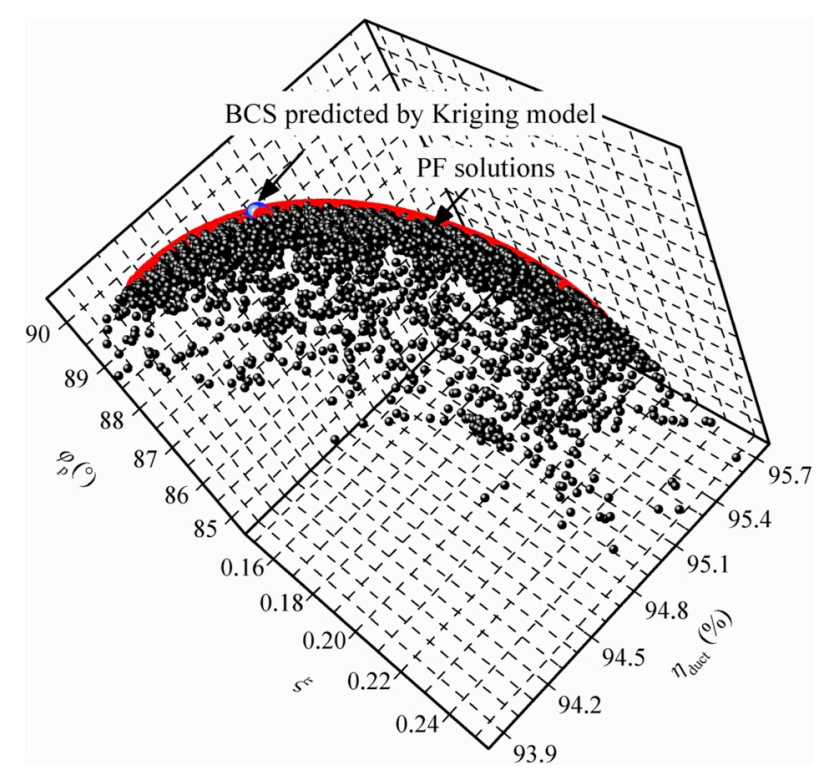

Fig. 6. Multi-objective optimization results for the intake duct.

The performance evaluation indexes for an intake duct are hydraulic efficiency $\eta_{\text {duct }}$, outflow nonuniformity $\xi$ and perpendicularity $\phi_{\mathrm{p}}$, which are defined in Eq. (5) (6), where $E_{\text {in }}$ is the total energy at the inlet plane positioned one impeller diameter forward of the ramp tangent point, $E_{\text {out }}$ is the total energy at the outlet plane, $\rho$ is fluid density, $V_{\text {in }}$ and $V_{\text {out }}$ is the velocity at the inlet plane and outlet plane, respectively, $p_{\text {in }}$ and $p_{\text {out }}$ is the static pressure at the inlet plane and outlet plane,

respectively, $p_{\mathrm{r}}$ is the reference pressure, $V_{\mathrm{a}}, \bar{V}_{\mathrm{a}}$ and $V_{\mathrm{t}}$ is the axial velocity, the averaged axial velocity and the tangential velocity at the outlet plane, respectively. The lower the nonuniformity and the larger the perpendicularity, the better the outflow quality. An excellent intake duct requires high hydraulic efficiency and good outflow quality. The optimization objectives in present paper is to reduce the outflow nonuniformity and improve the outflow perpendicularity together with the hydraulic efficiency.

$\eta_{\text {duct }}=\frac{E_{\text {out }}}{E_{\text {in }}}=\frac{\int\left[0.5 \bullet \rho V_{\text {out }}^{2}+\left(p_{\text {out }}-p_{\mathrm{r}}\right)\right] d Q}{\int\left[0.5 \bullet \rho V_{\text {in }}^{2}+\left(p_{\text {in }}-p_{\mathrm{r}}\right)\right] d Q}$

$\xi=\frac{1}{Q} \int_{d A}\left|V_{\mathrm{a}}-\bar{V}_{\mathrm{a}}\right| d A$

$\phi_{\mathrm{p}}=\frac{1}{Q} \int_{d A} V_{\mathrm{a}}\left[90^{\circ}-\arctan \left(\frac{V_{\mathrm{t}}}{V_{\mathrm{a}}}\right)\right] d A$

\subsection{CFD simulation}

For the prediction of the intake duct performance, the CFD technique is used in order to build the approximate model between the design variables and the optimization objectives based on the Design of Experiments (DOE) table and also to validate the optimized design scheme. The three-dimensional computational domain is shown in Fig. 2, including the water tank, the intake duct and the outlet pipe. The inlet plane of the water tank is $25 D$ forward of the intake duct with a $10 D$ (width) $\times 8 D$ (height) cross-section as recommended by Liu et al. (2010). The outlet pipe is $10 D$ long for computational stability.

As for the boundary conditions, a velocity profile is set at the inlet plane of the water tank to simulate the development of the boundary layer along the hull surface, and its definition is written in Eq. (8) (Bulten, 2006), where $V_{\mathrm{wt}}$ is the local velocity at the inlet plane of the water tank with a distance of $y_{\text {rel }}$ from the hull, $V_{s}$ is the ship navigation speed, $\delta$ is the thickness of the hull boundary layer, $L_{\text {in }}$ is the distance from the domain inlet plane to the inlet, $L_{\text {in }}=25 D$, Re is Reynolds number, $R e=V_{\mathrm{s}} L_{\mathrm{in}} / v, v$ is the fluid kinematic viscosity. Free slip walls are set at the bottom and lateral surfaces of the water tank, so grids near these walls can be relatively coarse without resolving the boundary layer. The no-slip wall is set at the tank upper surface and the static pressure is assigned at the tank outlet plane. The mass flow rate is used at the exit of the outlet pipe which is calculated by the Inlet Velocity Ratio, $\mathrm{IVR}=V_{\mathrm{p}} / V_{\mathrm{s}}=0.7$, where $V_{\mathrm{p}}$ is the averaged outflow velocity of the outlet pipe. The other solid walls are nonslip conditions.

$$
\begin{aligned}
& \left\{\begin{array}{l}
V_{\mathrm{wt}}=V_{\mathrm{s}}\left(y_{\mathrm{rel}} / \delta\right)^{1 / 9}, y_{\mathrm{rel}} \leq \delta \\
V_{\mathrm{wt}}=V_{\mathrm{s}}, y_{\mathrm{rel}}>\delta
\end{array}\right. \\
& \delta=0.27 L_{\mathrm{in}} \bullet \operatorname{Re}^{-1 / 6}
\end{aligned}
$$

Continuity and momentum equations for the incompressible flows are in Eq. (9)

$$
\begin{aligned}
& \frac{\partial u_{i}}{\partial x_{i}}=0 \\
& \frac{\partial\left(\rho u_{i}\right)}{\partial t}+\frac{\partial\left(\rho u_{i} u_{j}\right)}{\partial x_{i}}=-\frac{\partial p}{\partial x_{i}}+\frac{\partial}{\partial x_{j}}\left[\left(\mu+\mu_{t}\right)\left(\frac{\partial u_{i}}{\partial x_{j}}+\frac{\partial u_{j}}{\partial x_{i}}\right)\right]+f_{i}
\end{aligned}
$$

where $u_{i}$ is the velocity component in the $i$ direction, $p$ is the pressure, $f_{i}$ is the body force, $\rho$ is density, $\mu$ is the laminar viscosity and $\mu_{\mathrm{t}}$ is the turbulent viscosity. As stated in Eq. (9), the gravity is considered as the body force $f_{i}$ in the governing equations. In order to consider the gravity in the simulation setup, we specify the gravity vector in the rigid body coordinate frame that defines the downward direction and the magnitude of free-fall acceleration due to gravity, i.e., $f_{\mathrm{y}}=-\rho g$ where $g$ is the gravity acceleration.

To simulate the incompressible flows in the intake duct, the SST $k-\omega$ turbulence model is selected to enclose the Navier-Stokes equations,

\section{Table 4}

The structure parameters of the original and the optimized intake duct.

\begin{tabular}{lllllllll}
\hline & $\alpha_{\text {duct }}$ & $h_{\text {lip }}$ & $R_{2}$ & $R_{3}$ & $L_{0}$ & $L_{1}$ & $L_{2}$ & $L_{3}$ \\
\hline Original design & 25 & 39 & 1200 & 24 & 1064 & 1 & 557 & 155 \\
BCS & 33 & 28 & 1196 & 11 & 954 & 163 & 256 & 165 \\
\hline
\end{tabular}

Table 5

Performance comparison between the original and the optimized intake duct.

\begin{tabular}{llll}
\hline Objective & Original intake duct & BCS & \\
\cline { 3 - 4 } & & CFD value & Approximate value \\
\hline$\xi$ & 0.223 & 0.161 & 0.155 \\
$\phi_{\mathrm{p}}$ & 85.62 & 88.25 & 89.64 \\
$\eta_{\text {duct }}$ & 94.84 & 94.91 & 94.77 \\
\hline
\end{tabular}

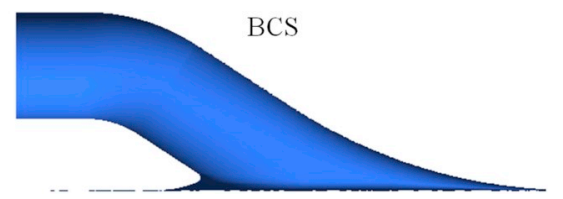

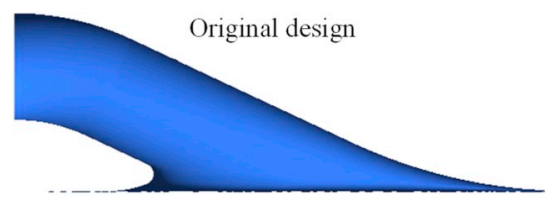

Fig. 7. Comparison between the original intake duct and the best compromise solution (BCS). 

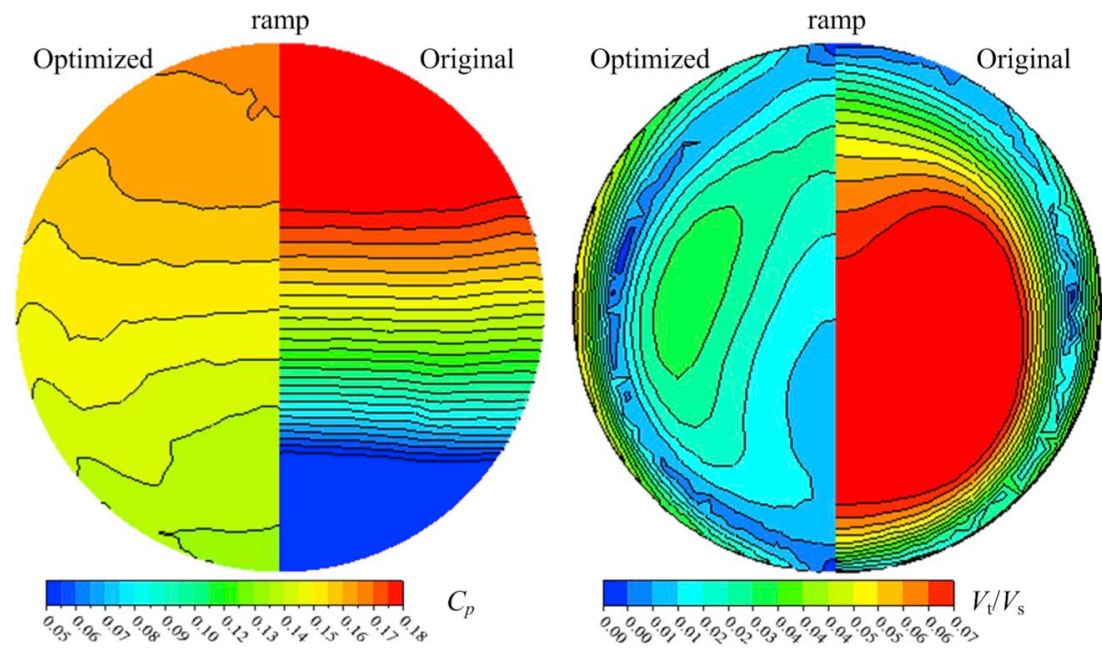

Fig. 8. Pressure and velocity distributions at the outlet plane of the intake duct (IVR $=0.7, V_{\mathrm{s}}=19.49 \mathrm{~m} / \mathrm{s}$ ).

since it can accurately predict flow separation with considering the transport of turbulent shear stress. A high resolution scheme is set for the advection term with the turbulence numeric. The convergence criterion is $1 \times 10^{-6}$. All the calculations are conducted by the commercial software CFX 14.0 on servers with 12 Intel Xeon X5670 core processors and a $160 \mathrm{G}$ hard drive, which is supported by Tsinghua National Laboratory for Information Science and Technology.

In present paper, hybrid grids are generated for the waterjet pump system by using the commercial software ICEM CFD. Structural grids are generated in the outlet pipe and the water tank, and unstructured grids are generated in the intake duct with prism grids refined near the nonslip walls as shown in Fig. 3. It should be noted that a boundary layer mesh is used to ensure that the non-dimensional normal distance from the non-slip wall, $\mathrm{y}^{+}$, is suitable with the "automatic near-wall treatment for the SST omega-based model" used for the wall treatment. The $\mathrm{y}^{+}$for the non-slip wall is controlled within 15-90.

The investigation of mesh influence is performed by monitoring the hydraulic efficiency $\eta_{\text {duct }}$ outflow nonuniformity $\xi$ and perpendicularity $\phi_{\mathrm{p}}$. Five mesh resolutions are tested as shown in Table 2. It is found that the relative error of hydraulic efficiency $\eta_{\text {duct }}$ and outflow perpendicularity $\phi_{\mathrm{p}}$ is very small when compared to case 5 , and the relative error of outflow nonuniformity $\xi$ decreases to $4.35 \%$ for case 4 , Thus, case 4 is selected as the final mesh, and the final grid elements are about 3.7 million.

\subsection{Multi-objective optimization system}

The proposed multi-objective optimization strategy is shown in Fig. 4 which is combined with Design of Experiments (DOE), Computational Fluid Dynamics (CFD), three-dimensional parametric design, approximate model, the modified Non-dominated Sorting Genetic Algorithm-II (NSGA-II) and a Technique for Ordering Preferences by Similarity to Ideal Solution (TOPSIS).

Step 1. Parametric design of the intake duct. The geometric parameters discussed in section 2.1 are treated as the design variables. The hydraulic efficiency $\eta_{\text {duct }}$, the outflow nonuniformity $\xi$ and perpendicularity $\phi_{\mathrm{p}}$ are selected as the optimization objectives. Thus, there are eight variables including four host variables and four dependent variables and three optimization objectives.

Step 2 . To reduce the design and calculation workload and make the sample points evenly distributed in the design space, a Design of Experiments (DOE) table with the sample size of 75 is created by using the Optimal Latin Hypercube Design (Opt LHD) method based on the ranges of four host variables listed in Table 1 . The three- dimensional geometries of these sample points are established in bulk by the expression function in UG NX 6.0 with the hybrid grids meshed by ICEM CFD 14.0, and then the corresponding hydraulic efficiency together with the outflow quality are predicted by the CFD technique.

Step 3. Taking the design variables of 75 sample points as the input signal and the corresponding optimization objectives (i.e. hydraulic efficiency, nonuniformity and perpendicularity) as the output signal, the approximate model between the design variables and the optimization objectives is fitted by Kriging Model.

Step 4. To ensure the uniform distribution of Pareto optimal solutions, the NSGA-II algorithm is modified by the dynamic crowding distance with details described by Huang et al. (2015). The improved NSGA-II algorithm is introduced to globally search in the design space for the Pareto Front (PF). Note that the performance (i.e. hydraulic efficiency, nonuniformity and perpendicularity) is predicted by the Kriging Model built in Step 3 instead of the CFD technique during the optimization process. The parameters for the improved NSGA-II algorithm are set up in Table 3.

Step 5. Instead of randomly selecting one solution from the Pareto Front to implement, a Technique for Ordering Preferences by Similarity to Ideal Solution (TOPSIS) is introduced to select the best compromise solution (BCS) that is not only shortest to the positive ideal solution but also longest to the negative ideal solution with objective weights computed by Shannon's entropy method. Details about the TOPSIS method refer to literature (Li, 2009). Then, the best compromise solution is validated using the CFD technique and compared with the original design.

\section{Results and discussion}

\subsection{Sensitivity analysis}

The local sensitivity is analyzed to study the effects of each design variable on the optimization objective and results are shown in Fig. 5. In other words, the effect of each design variable on the optimization objectives (i.e. the hydraulic efficiency $\eta_{\text {duct }}$, the outflow nonuniformity $\xi$ and perpendicularity $\phi_{\mathrm{p}}$ ) is discussed in sequence by keeping the other design variables unchanged.

The $R_{2}$ has the greatest impact on the nonuniformity and followed by the $\alpha_{\text {duct; }}$; while the $R_{3}$ and $h_{\text {lip }}$ have little effect on the outflow nonuniformity. The smaller $R_{2}$ is, the better it is to reduce the nonuniformity. The nonuniformity reaches a minimum when $\alpha_{\text {duct }}=33.03^{\circ} . R_{2}$ has the greatest impact on the outflow perpendicularity $\phi_{\mathrm{p}}$ and followed by $\alpha_{\text {duct }}$ and $R_{3}$, while $h_{\text {lip }}$ has little effect on the perpendicularity. The 


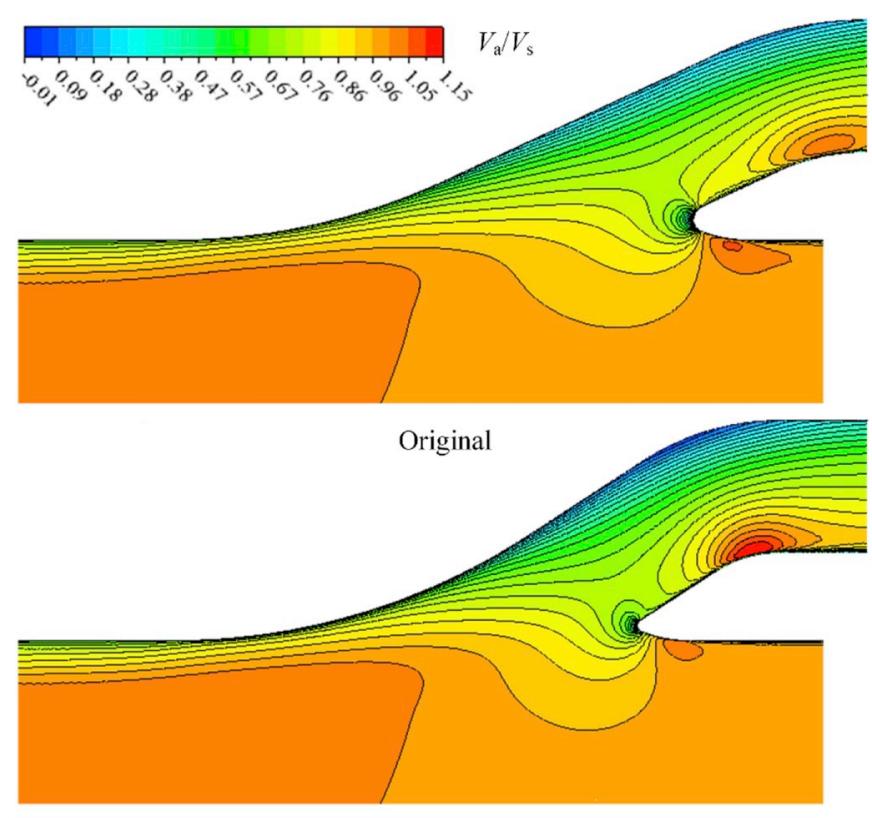

Optimized

(a)
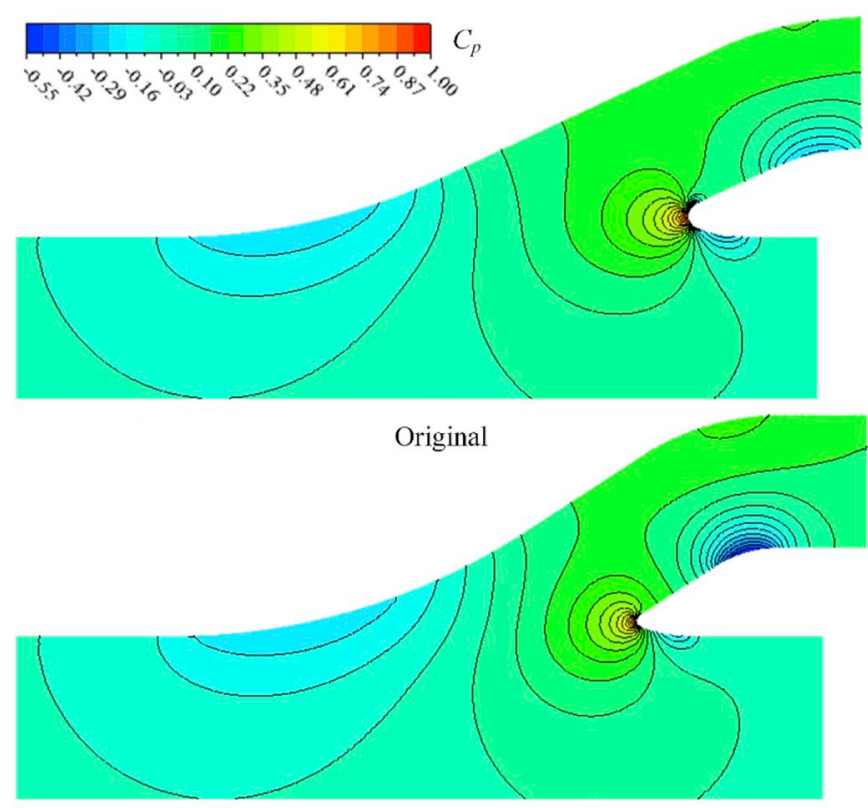

Optimized

(b)

Fig. 9. Velocity and pressure distributions at the midplane of the intake duct $\left(\mathrm{IVR}=0.7, V_{\mathrm{s}}=19.49 \mathrm{~m} / \mathrm{s}\right)$.

smaller $R_{2}$, the better the perpendicularity, and it is improved with the increasing $R_{3}$. The perpendicularity reaches a maximum of $88.30^{\circ}$ when $\alpha_{\text {duct }}=33.29^{\circ} . R_{3}$ has the greatest impact on the hydraulic efficiency $\eta_{\text {duct }}$ and followed by $\alpha_{\text {duct }}, h_{\text {lip }}$ and $R_{2}$. The hydraulic efficiency reduces with the increase of $R_{3}, \alpha_{\text {duct }}$ and $h_{\text {lip }}$, while it increases with the increasing $R_{2}$.

Sensitivity analysis indicates that $\alpha_{\text {duct }}$ has obvious impact on the three optimization objectives (i.e. the hydraulic efficiency $\eta_{\text {duct }}$ the outflow nonuniformity $\xi$ and perpendicularity $\phi_{\mathrm{p}}$ ) while $h_{\text {lip }}$ has little impact on the three optimization objectives. Besides, $R_{2}$ and $R_{3}$ play an opposite role for a certain optimization objective.

\subsection{Performance and internal flows}

The improved NSGA-II algorithm is used for global search in the design space with the optimization results shown in Fig. 6. Black dots represent the traversal process, red dots indicate the Pareto Front, and the blue dot is the best compromise solution (BCS) determined by the TOPSIS method. Herein, TOPSIS (Li, 2008) is to evaluate all pareto-front (PF) sets and determine the best compromise solution that is not only shortest to the positive ideal solution but also longest to the negative ideal solution with objective weights computed by Shannon's entropy method. The weight of the hydraulic efficiency $\eta_{\text {duct }}$, the outflow nonuniformity $\xi$ and perpendicularity $\phi_{\mathrm{p}}$ is $0.12,0.78,0.19$, respectively. As shown at Fig. 6, the location of the best compromise solution (BCS) at the pareto-front is near the largest nonuniformity $\xi$ due to its higher entropy weight (0.78). The geometric structures of the original intake duct and the best compromise solution (BCS) are shown in Fig. 7, and their structural parameters are listed in Table 4. As for the BCS design, the inclination angle between the duct axis and the hull $\alpha_{\text {duct }}$ is larger and the length of the horizontal straight section $L_{1}$ is longer when compared with the original design.

Their hydraulic performance is compared in Table 5. For the best compromise solution (BCS), the prediction error between the CFD technique and Kriging model is $0.15 \%, 3.73 \%$ and $1.58 \%$ for the hydraulic efficiency $\eta_{\text {duct }}$ the outflow nonuniformity $\xi$ and perpendicularity $\phi_{\mathrm{p}}$, respectively. It is indicated that the Kriging model is reliable to predict the optimization objectives of new individuals during the global search process. At the design condition of IVR $=0.7, V_{\mathrm{s}}=19.49 \mathrm{~m} / \mathrm{s}$, the nonuniformity of the optimized intake duct is reduced by $27.8 \%$, the perpendicularity is increased by $3.07 \%$ and the hydraulic efficiency is slightly increased by $0.074 \%$ compared with the original intake duct. In other words, the nonuniformity, the perpendicularity and the hydraulic efficiency for the optimized intake duct is $0.161,88.25^{\circ}$ and $94.91 \%$, respectively. For the optimized intake duct, the horizontal straight section is longer which is beneficial for the outflow rectification, resulting in the dramatic improvement in the outflow quality.

Fig. 8 shows the pressure and velocity distributions at the outlet plane of intake duct at the design condition (IVR $=0.7, V_{\mathrm{s}}=19.49 \mathrm{~m} / \mathrm{s}$ ). Since the flow field on the outlet plane is symmetrically distributed, only one side is displayed with the optimized intake duct on the left and the original intake duct on the right. As for the optimized intake duct, the pressure on the outlet plane is very uniform and the tangential velocity is small without obvious secondary flow. In contrast, there is clear pressure gradient for the original intake duct with a significant high-velocity region in the center of the outlet plane. The relatively uniform distributions of the flow fields directly result in a $27.8 \%$ reduction in the nonuniformity and an increase of $3.07 \%$ in perpendicularity for the optimized intake duct compared with the original intake duct.

Fig. 9 shows the velocity and pressure distributions at the midplane of the intake duct under the condition: IVR $=0.7, V_{\mathrm{s}}=19.49 \mathrm{~m} / \mathrm{s}$. During the flow suction process, water firstly hits the lip and then flows through the elbow section as shown in Fig. 9 (a). For the original design, the inclination angle between the duct axis and the hull $\left(\alpha_{\text {duct }}\right)$ is smaller, water flows smoothly through the passage without creating an obvious low-pressure area. However, due to the larger inclination angle between the duct axis and the hull $\left(\alpha_{\text {duct }}\right)$ and the longer length of the horizontal straight section $\left(L_{1}\right)$ for the optimized duct, obvious low-pressure area occurs at the lower side of the elbow section, resulting in local highspeed zone and flow separation. The hydraulic efficiency for the original duct is $94.84 \%$ and the hydraulic efficiency for the optimize duct is $94.91 \%$. It is noted that the flow separation at the lower side of the elbow section is the primary source of the hydraulic loss for the optimized duct and this provides guidance for the further optimization.

In practice, the intake duct is operated under various conditions. It is necessary to evaluate the performance of intake duct at various IVRs. Fig. 10 shows the performance of adapting to various IVRs ranging from 0.3 to 1.5 . Compared with the original intake duct, the nonuniformity of 

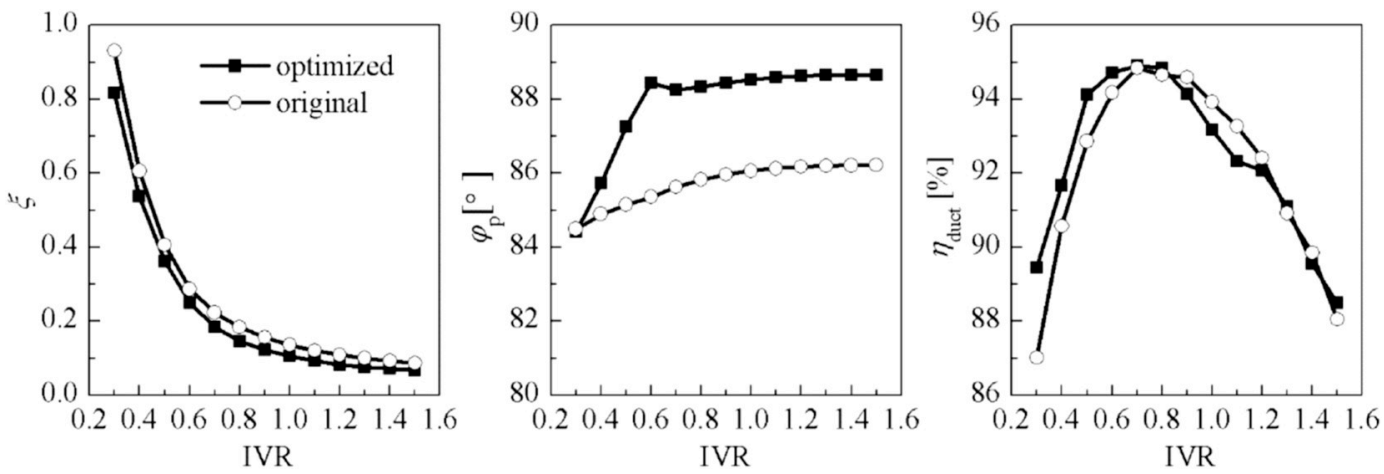

Fig. 10. Comparisons of hydraulic performance between the optimized and original intake duct at various IVRs.

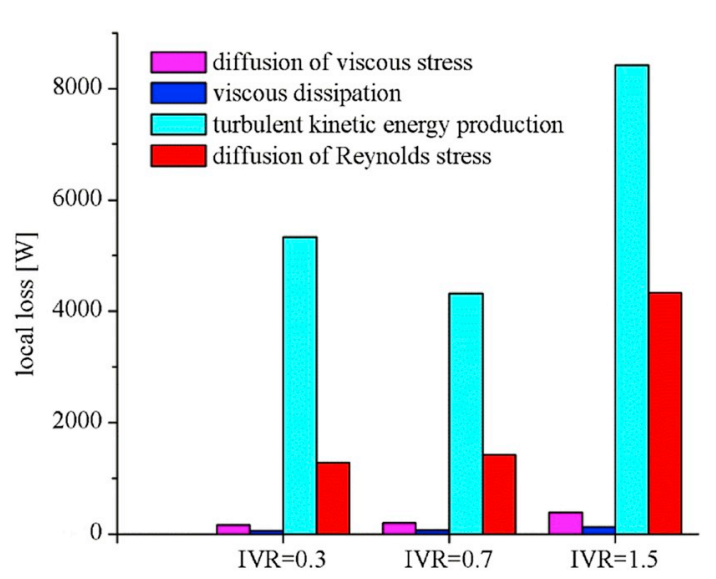

Fig. 11. Composition of the local loss at three conditions (i.e. IVR $=0.3,0.7$ and 1.5) for the optimized duct.

the optimized intake duct is slightly reduced with an obvious increase in the perpendicularity. Hydraulic efficiency of the optimized intake duct is larger than the original one during IVR $=0.3-0.8$, then becomes slightly smaller during IVR $=0.9-1.2$, and there is little difference between the two intake ducts when IVR $>1.2$. Chang et al. (2010) investigated IVR effects on the intake duct performance and pointed out that the intake duct should be operated during IVR $=0.6-0.8$ since it is likely to generate the flow separation under low IVRs and cavitation occurs under high IVRs. Therefore, when compared with the original design, the optimized intake duct performs both better outflow quality and hydraulic efficiency during IVR $=0.3-0.8$.

\subsection{Physical analysis of head losses in the optimized intake duct}

To better understand the relationship between the flow patterns and the loss in the intake duct, a local loss analysis based on the energy equation is conducted at various IVRs for the optimized duct. A detailed energy equation was established by Wilhelm et al. (2016) to investigate the local loss in a draft tube and Lu et al. (2019) developed this energy equation by considering the variation of the kinetic energy of the mean flow to study the highly time dependent rotating stall in a model pump-turbine.

For an incompressible turbulent flow without heat transfer or temperature variation, the energy equation in stationary hydraulic components can be written as follows:

$$
\begin{aligned}
P_{\mathrm{L}} & =-\iiint_{V} \frac{\partial\left(-\overline{u_{i}} \rho \overline{u_{i} u_{j}^{\prime}}\right)}{\partial x_{j}} d V-\iiint_{V} \mu \frac{\partial\left(\overline{u_{i}} \overline{D_{i j}}\right)}{\partial x_{j}} d V+\iiint \int_{V}\left(-\rho \overline{u_{i} u_{j}^{\prime}}\right) \frac{\partial \overline{u_{i}}}{\partial x_{j}} d V \\
& +\iiint_{V} \mu \overline{D_{i j}} \frac{\partial \overline{u_{i}}}{\partial x_{j}} d V
\end{aligned}
$$

$D_{i j}=\frac{\partial u_{i}}{\partial x_{j}}+\frac{\partial u_{j}}{\partial x_{i}}$

$-\rho \overline{u_{i} u_{j}^{\prime}}=\mu_{\mathrm{t}}\left(\frac{\partial \overline{u_{j}}}{\partial x_{i}}+\frac{\partial \overline{u_{i}}}{\partial x_{j}}\right)-\frac{2}{3} \delta_{i j} \rho k$

where $P_{\mathrm{L}}$ stands for the power loss, $k$ is the turbulent kinetic energy. $\delta_{i j}$ is Kronecker function, $\bar{u}_{i}$ and $u^{\prime}$ are the time averaged value and the fluctuation of velocity $u$, respectively. $D_{i j}$ is a shear strain tenor. Based on the Boussinesq approximation, Reynolds stress $\rho \overline{u_{i}^{\prime}} u_{j}^{\prime}$ is calculated according to Eq. (12).

On the right-hand side of Eq. (10), the first term and second term is the diffusion of the Reynolds stress and viscous stress. The third term represents the turbulent kinetic energy production, which is responsible for the transfer of the kinetic energy of the mean flow to the turbulent kinetic energy. And the last term is the viscous dissipation.

Fig. 11 illustrates the local loss components at three conditions, that is IVR $=0.3,0.7$ and 1.5, for the optimized duct. It is shown that the turbulent kinetic energy production and the diffusion of the Reynolds stress are much larger than the other two terms, indicating that the transportation and dissipation process of total pressure in the intake duct is mainly dominated by the turbulence effect and most loss of the energy converts to the turbulent kinetic energy.

The distributions of the diffusion of the Reynolds stress and the turbulent kinetic energy production at three conditions (i.e. IVR $=0.3$, 0.7 and 1.5) are shown in Fig. 12. The streamlines with the velocity vectors are shown in Fig. 13. Here $P_{L 1}=\partial\left(\overline{u_{i}} \rho \overline{u_{i}} u_{j}^{\prime}\right) / \partial x_{j}$ indicates the Reynolds stress diffusion and $P_{L 3}=\left(-\rho \overline{u_{i}^{\prime}} u_{j}^{\prime}\right) \partial \bar{u}_{i} / \partial x_{j}$ represents the turbulent kinetic energy production. From Fig. 12(a), the duct inflow at the upstream corresponds to a high Reynolds stress diffusion and this region decreases with the IVR increasing. Inside the elbow section of the optimized duct, the high $-P_{\mathrm{L} 1}$ region is larger at IVR $=0.3$ and 1.5 than that at IVR $=0.7$. It is noted that there is an adjacent region between the high- $P_{\mathrm{L} 1}$ region and the low $-P_{\mathrm{L} 1}$ region for IVR $=0.3$, and the region size is similar to each other. As shown in Fig. 13 (a), a large flow separation region occurs inside the duct elbow section. It indicates that the mean motion energy of the high-velocity primary flow transfers to the lowvelocity separation flow by the Reynolds stress diffusion. A high- $P_{\mathrm{L} 3}$ region is located inside the duct elbow channel and the duct lip at IVR $=0.3$ as shown in Fig. 12(b), and the high- $P_{\mathrm{L} 3}$ region is smallest at IVR $=0.7$ when compared to the other two IVRs. Based on the streamlines and velocity distributions in Fig. 13, it is demonstrated that the impingement of the flow to the duct lip and the interaction between the separation flow (with low flow velocity) and the primary flow (with high flow velocity) are the main reason for dissipating the energy of mean motion to other forms. 


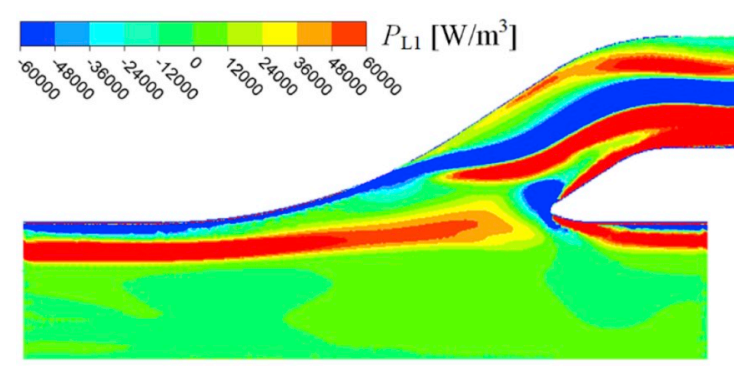

$\operatorname{IVR}=0.3$

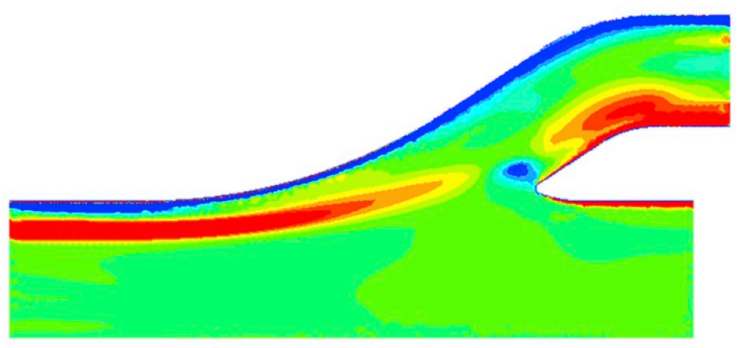

IVR $=0.7$

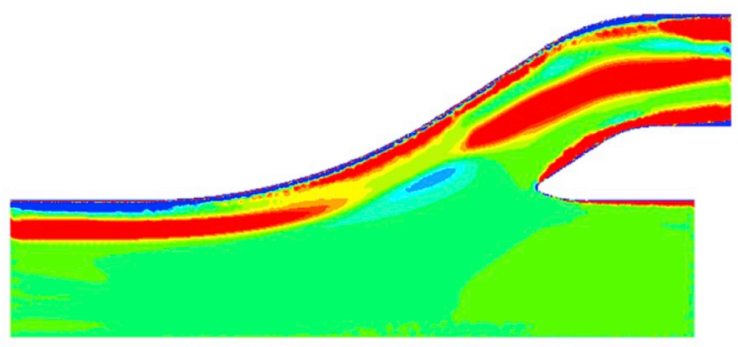

$\operatorname{IVR}=1.5$

(a)

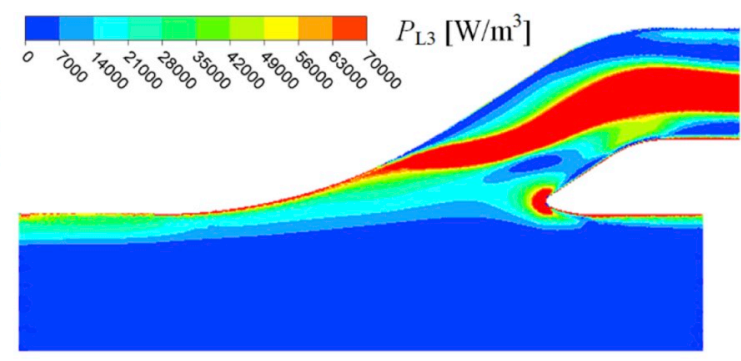

$\operatorname{IVR}=0.3$

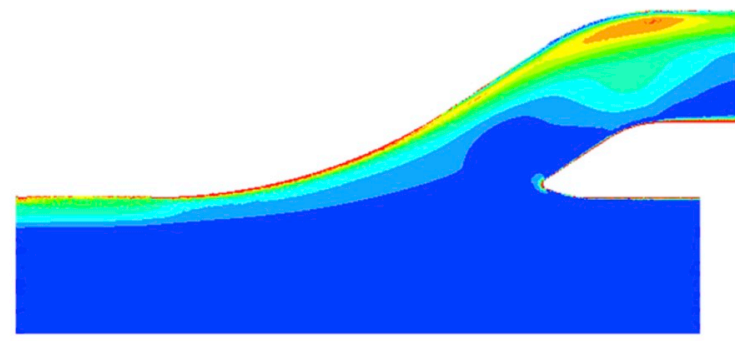

IVR $=0.7$

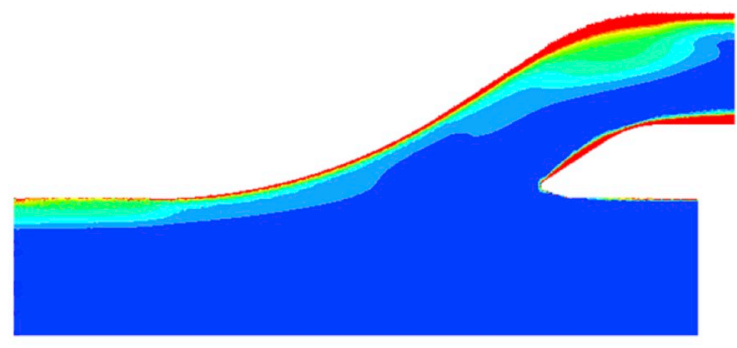

$\operatorname{IVR}=1.5$

(b)

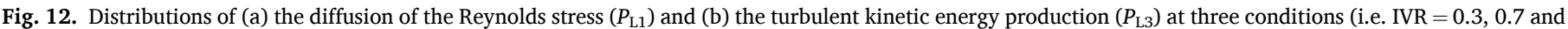
1.5) for the optimized duct.

\subsection{Applications in a waterjet propulsion system}

Both the original and the optimized intake duct are used in combination with a mixed-flow waterjet propulsion system in order to analyze the effect of intake duct on the waterjet pump and the system. The threedimensional computational domain is shown in Fig. 14, including the water tank, the intake duct, the mixed-flow waterjet pump and the nozzle with its exit diameter of $0.157 \mathrm{~m}$. The boundary conditions are mentioned in section 2.2. When the power of the waterjet propulsion system is $310.4 \mathrm{~kW}$, four calculation conditions are selected from the sailing characteristic curve in Fig. 15 with the corresponding navigation speeds and rotational speeds listed in Table 6.

The performance of intake duct in the waterjet propulsion system is shown in Fig. 16. When the intake duct is combined with a mixed-flow waterjet propulsion system, hydraulic efficiency of the optimized intake duct decreases by $20.4 \%$ on average with the perpendicularity increased by an average of $4.11 \%$ compared with the original intake duct. Note that the optimized intake duct performs a better outflow quality, which leads to an increase of $0.086 \%$ in the waterjet pump efficiency as shown in Fig. 17. However, the non-uniform inflow caused by different intake duct has little effect on hydraulic efficiency of the mounted pump, and this is in accordance with conclusions made by Van Esch (2009). At $V_{\mathrm{s}}=17.49 \mathrm{~m} / \mathrm{s}$, the efficiency of the optimized intake duct is lower than the original one; however, with further increase of the navigation speed, the efficiency of the optimized intake duct becomes higher.

Fig. 18 shows the velocity distributions at the outlet plane of the intake duct in the waterjet propulsion system. When $V_{\mathrm{s}}=17.49-23.15 \mathrm{~m} / \mathrm{s}$, the tangential velocity at the outlet plane (i.e. $V_{\mathrm{t}}$ ) is low at the bottom and high at the top. This is because the flow is affected by the inertial force during the inhalation process, resulting in low-pressure below and high-pressure above. Note that the velocity is asymmetrically distributed due to effects from rear rotating waterjet impeller. Besides, due to the interference of the rotation axis, circulation occurs when the water flows around the rotating shaft, which results in a low-velocity region at the rear (above the axis shown in Fig. 18). With the increasing navigation speed, the high-velocity region at the outlet plane is gradually reduced and the low-velocity region is gradually expanded. Compared the intake duct before and after optimization, the velocity difference becomes smaller at the outlet plane after optimization.

Pressure distributions at the impeller pressure surface and suction surface are depicted at various navigation speeds in Fig. 19 and Fig. 20. With the increasing navigation speed, the pressure on the suction surface increases, while the pressure on the pressure surface gradually decreases. Due to the combined effect of non-uniform inflows and the gravity, the pressure on the six blades is different. The pressure on the suction surface is high at the bottom and low at the top while the pressure on the pressure surface is distributed conversely. The intake duct mainly affects the flow pattern on the suction surface of the impeller blade. After the optimization, the outflow provided by the intake duct is much uniform, resulting in a uniform pressure distribution on the suction surface of impeller blade. At $V_{\mathrm{s}}=17.49 \mathrm{~m} / \mathrm{s}$, the low- 


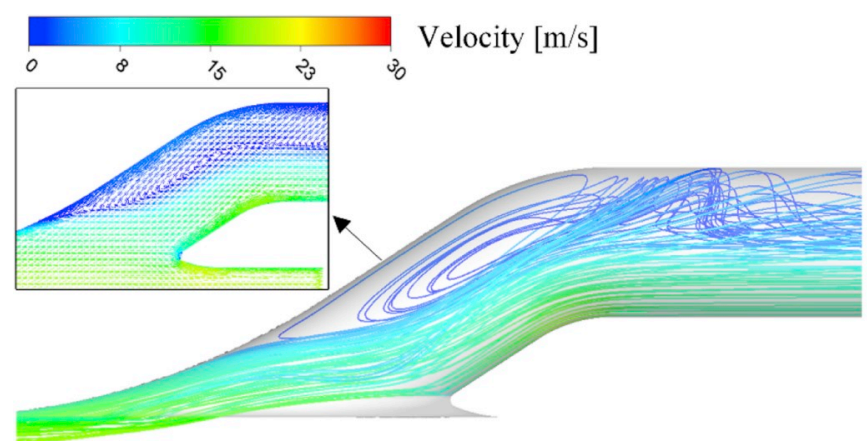

(a) $\mathrm{IVR}=0.3$

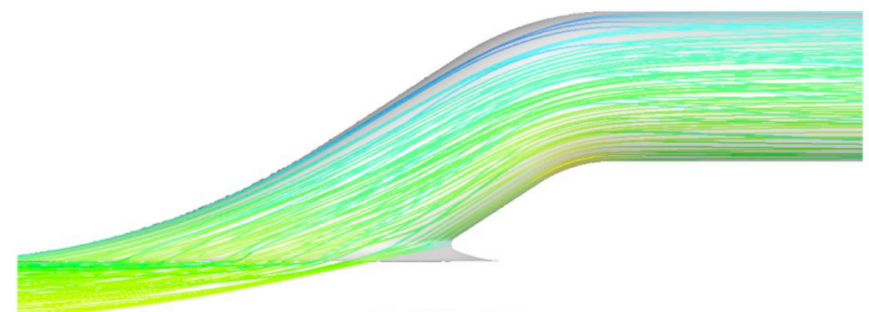

(b) $\mathrm{IVR}=0.7$

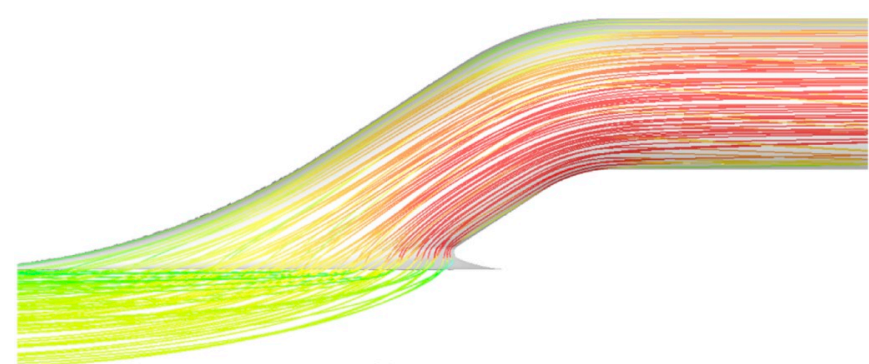

(c) IVR $=1.5$

Fig. 13. Streamlines with the velocity vectors at the midplane at three conditions (i.e. IVR $=0.3,0.7$ and 1.5) for the optimized duct.

pressure region is obviously decreased after optimization, indicating that the optimized intake duct has a better cavitation performance since this condition is close to the cavitation limit curve as shown in Fig. 15. On the other hand, the intake duct has little effect on the pressure distribution of the pressure surface of impeller blade with a slight difference in value.

Total pressure variations at the inlet plane and outlet plane of the pump are shown in Fig. 21 to study the effects of different inflows on the pump performance. The pressure boundary is used at the nozzle exit, so the pressure variations at the nozzle exit are not discussed. S1 presents the pump inlet plane (i.e. the outlet plane) and S2 is the pump outlet plane. The total pressure at the pump inlet plane and outlet plane gradually increases with the increasing navigation speed. The flow rate in Fig. 17(a) and the shaft power in Fig. 21(b) increase as the navigation speed increases, but the shaft power grows faster than the total pressure, causing that the pump efficiency decreases with the increase of the navigation speed. As shown in Fig. 21(b), the pump efficiency is decreased by $2.7 \%$ when the navigation speed increases from $17.49 \mathrm{~m} / \mathrm{s}$ to $23.15 \mathrm{~m} / \mathrm{s}$. Based on comparisons of the intake duct before and after optimization, combined analyses of the total pressure and the internal flow fields indicate that different inflows have a greater impact on the suction surface other than the pressure surface of impeller blade, which is reflected in the difference of the shaft power, but the inflow has a smaller impact on the flow field inside the nozzle.

From the above explanations, the optimized duct design is suitable for different operating conditions. Based on the experiences of our coauthors from Science and Technology on Water Jet Propulsion Laboratory, both the duct and the waterjet pump are usually operated under non-cavitation conditions and cavitation can be avoided by changing the operating condition, so anti-cavitation performance was not considered as the optimization objective in this paper. Inevitably, there will always be extreme operating conditions in the waterjet pump system, such as cavitation conditions. From this point of view, we need to consider the

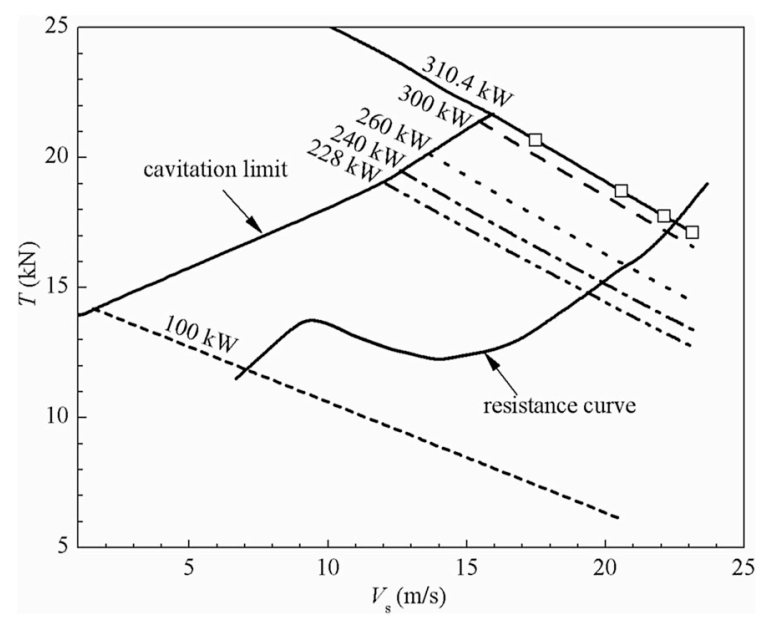

Fig. 15. Sailing characteristic curve.

Table 6

Calculation conditions of waterjet propulsion system.

\begin{tabular}{lll}
\hline$V_{\mathrm{s}}(\mathrm{knot})$ & $V_{\mathrm{s}}(\mathrm{m} / \mathrm{s})$ & $n(\mathrm{r} / \mathrm{min})$ \\
\hline 34 & 17.49 & 2809.30 \\
40 & 20.58 & 2818.82 \\
43 & 22.12 & 2824.86 \\
45 & 23.15 & 2829.37 \\
\hline
\end{tabular}

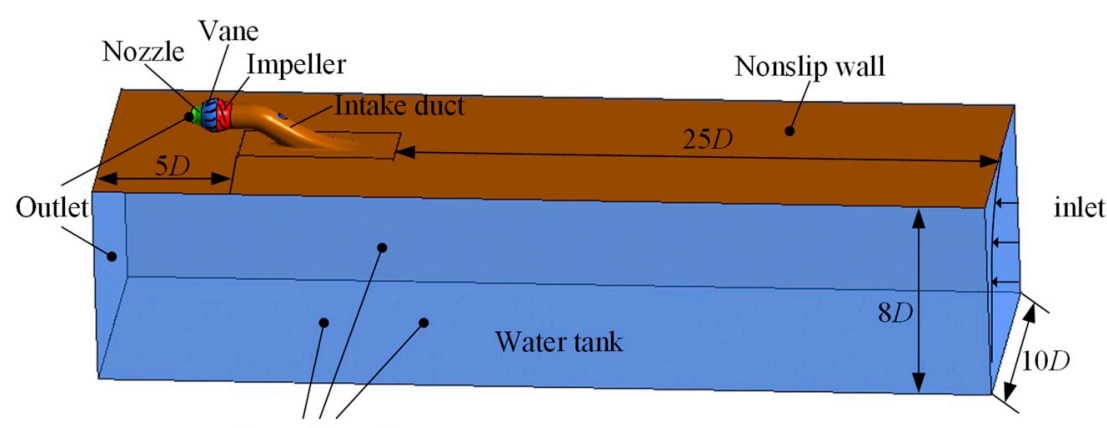

Free slip wall

Fig. 14. Computation domain for the waterjet propulsion system. 


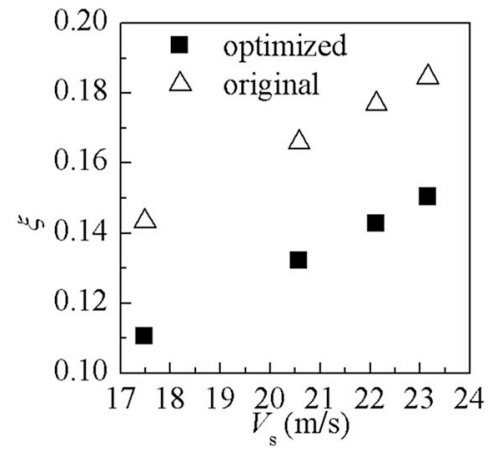

(a)

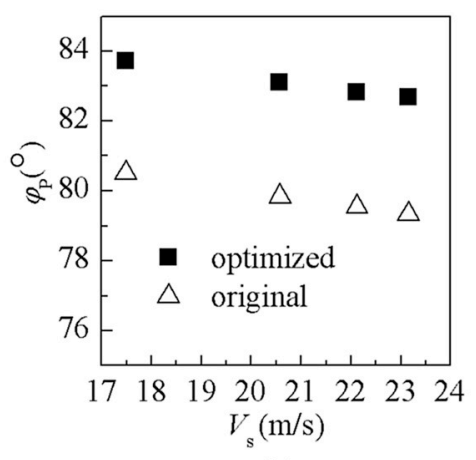

(b)

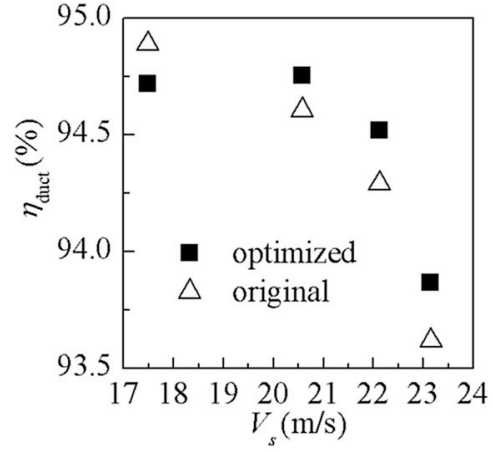

(c)

Fig. 16. Performance of intake duct in the waterjet propulsion system.

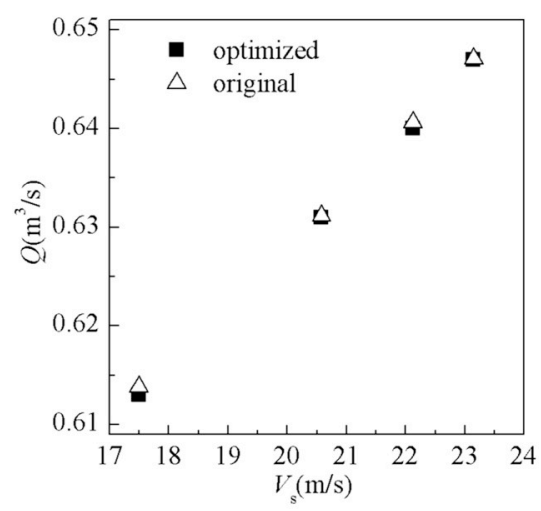

(a)

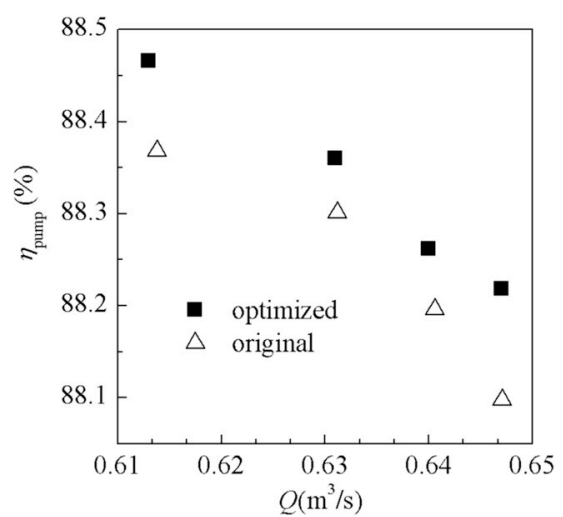

(b)

Fig. 17. Pump performance in the waterjet propulsion system.

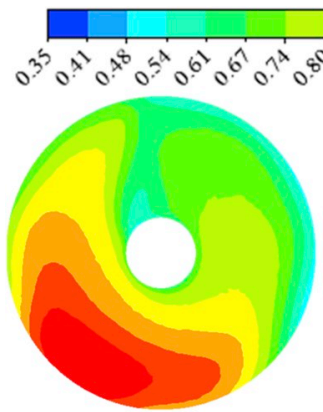

$17.49 \mathrm{~m} / \mathrm{s}$

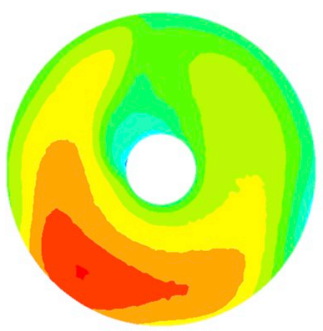

$17.49 \mathrm{~m} / \mathrm{s}$

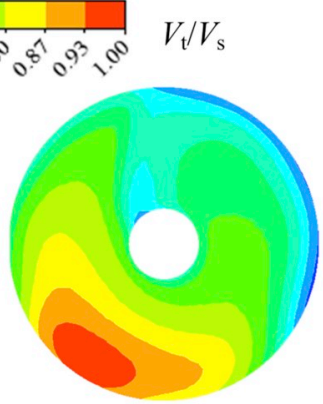

$20.58 \mathrm{~m} / \mathrm{s}$

(a) original duct

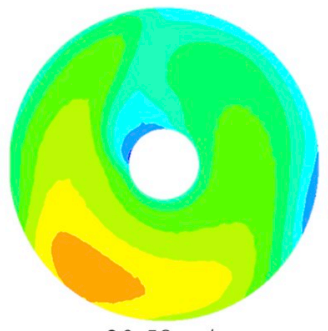

$20.58 \mathrm{~m} / \mathrm{s}$

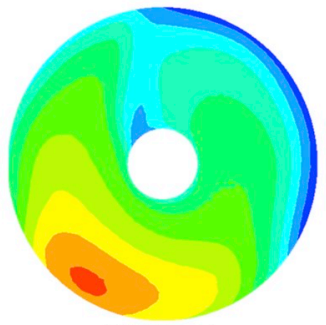

$22.12 \mathrm{~m} / \mathrm{s}$

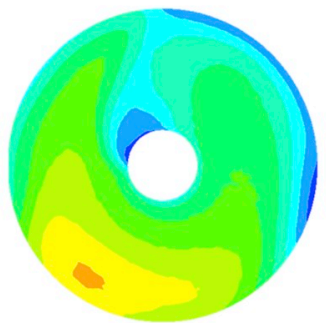

$22.12 \mathrm{~m} / \mathrm{s}$

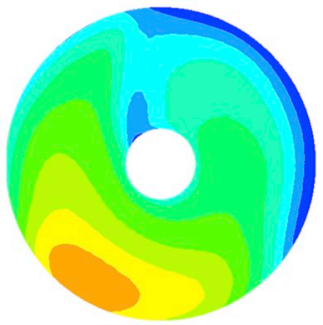

$23.15 \mathrm{~m} / \mathrm{s}$

(b) optimized duct

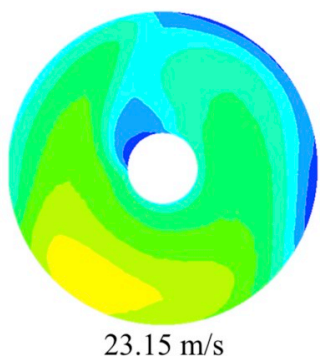

$23.15 \mathrm{~m} / \mathrm{s}$

Fig. 18. Tangential velocity distributions at the outlet plane of intake duct in the waterjet propulsion system. 

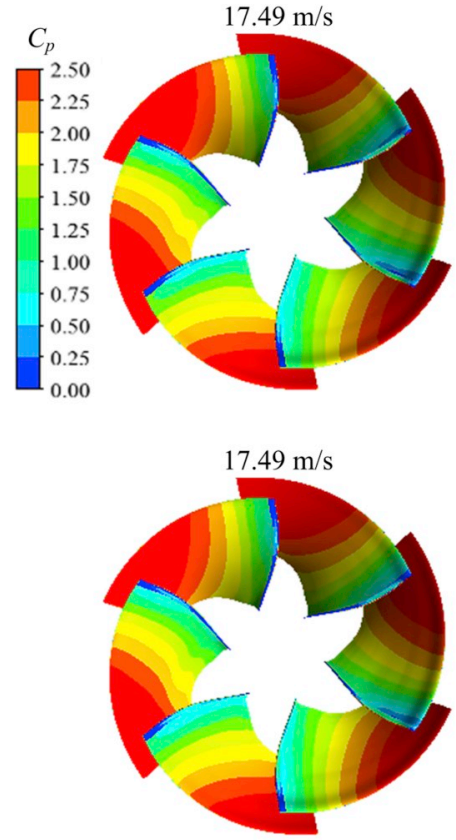

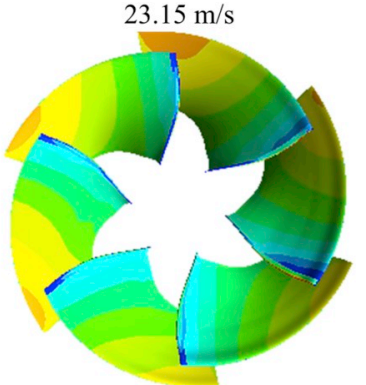

(a) original duct
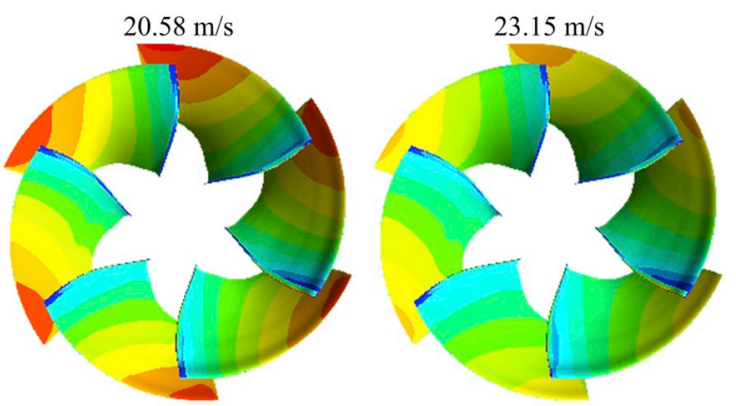

(b) optimized duct

Fig. 19. Pressure distributions at impeller blade pressure surface in the waterjet propulsion system.
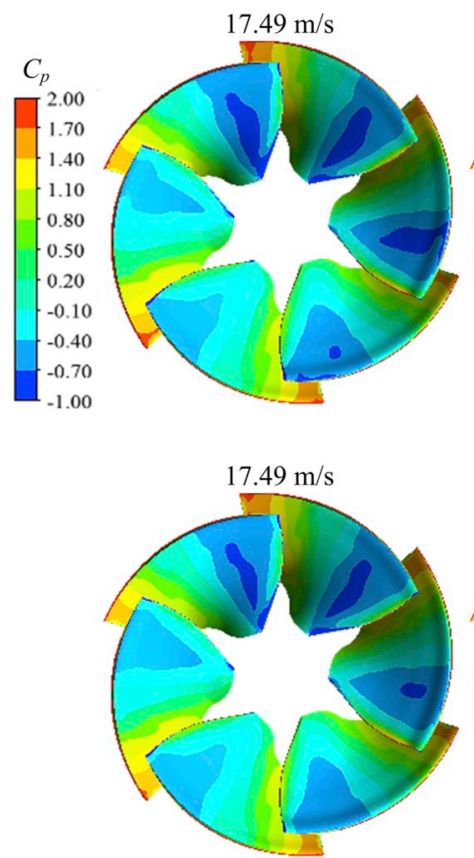

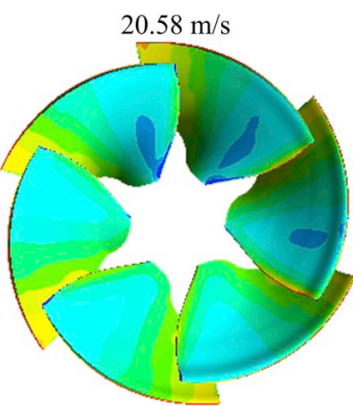

(a) original duct

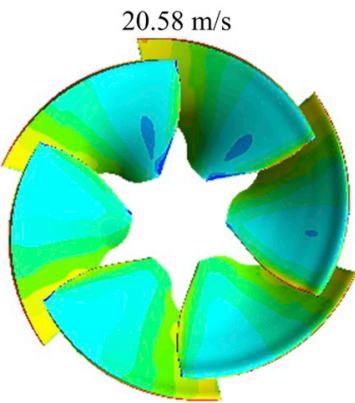

(b) optimized duct
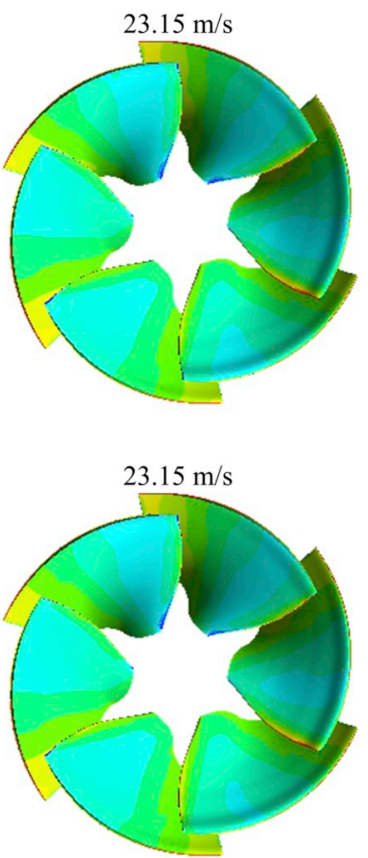

Fig. 20. Pressure distributions at impeller blade suction surface in the waterjet propulsion system.

anti-cavitation performance and take it as one of the optimization objectives. This is not however the focus of this paper and is the subject of future work.

\section{Conclusions}

This paper aims to optimize a flush-type intake duct by using the proposed multi-objective optimization system including Design of Experiments (DOE), Computational Fluid Dynamics (CFD), threedimensional parametric design, Kriging model, the modified Non- dominated Sorting Genetic Algorithm-II (NSGA-II) and a technique for Ordering Preferences by Similarity to Ideal Solution (TOPSIS). The optimization objectives are the outflow nonuniformity $\xi$ and the outflow perpendicularity $\phi_{\mathrm{p}}$ together with hydraulic efficiency of intake duct $\eta_{\text {duct }}$. Conclusions are as follows:

(1) Based on the sensitivity analysis, the optimization objectives are significantly affected by the inclination angle $\alpha_{\text {duct }}$ and slightly affected by the lip vertical distance $h_{\text {lip }}$. For a certain optimization 


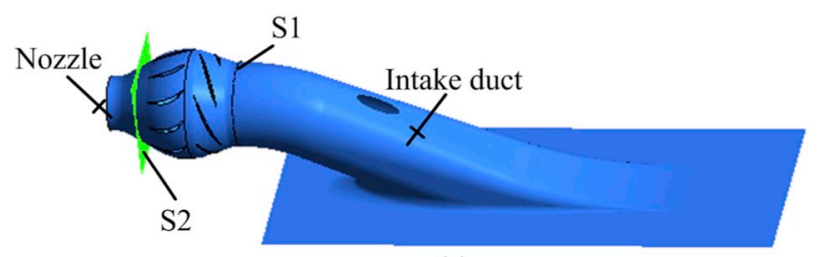

(a)

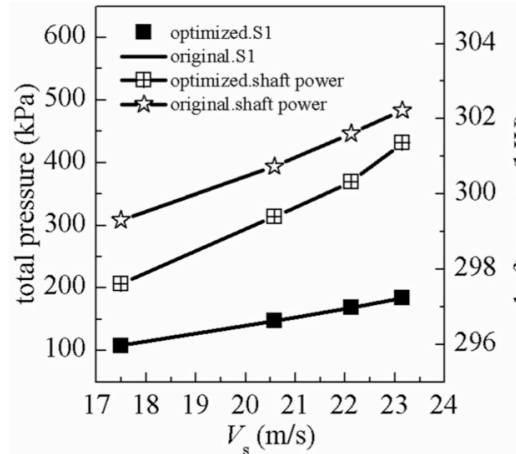

(b)

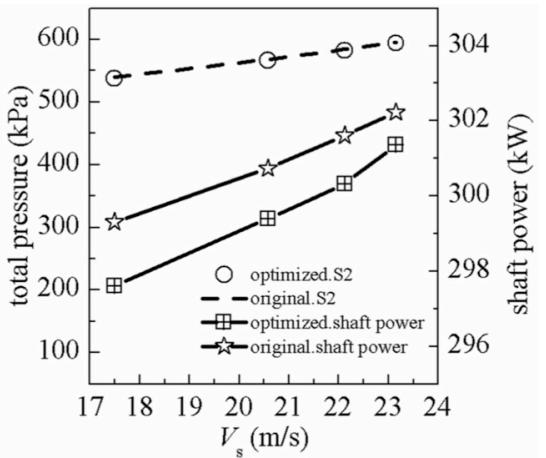

(c)

Fig. 21. Total pressure variations in the pump at various speeds. S1 presents the pump inlet plane (i.e. the outlet plane) and S2 is the pump outlet plane.

objective, the effect of the radius on the upper side of the ramp section $R_{2}$ and the lip radius on the upper side $R_{3}$ is opposite.

(2) Compared with the original intake duct, the optimized intake duct has a larger $\alpha_{\text {duct }}$ and a longer horizontal straight section; At the design condition of IVR $=0.7$ and $V_{\mathrm{s}}=19.49 \mathrm{~m} / \mathrm{s}$, the nonuniformity decreases by $27.8 \%$, the perpendicularity increases by $3.07 \%$, and hydraulic efficiency slightly increases for the optimized intake duct. The nonuniformity, the perpendicularity and the hydraulic efficiency after optimization are 0.161 , $88.25^{\circ}$ and $94.91 \%$, respectively.

(3) During IVR $=0.3-0.8$, the outflow quality and hydraulic efficiency of the optimized intake duct are greatly improved compared with the original intake duct.

(4) Based on the flow at the outlet plane of intake duct, the pressure distribution after optimization is very uniform and the tangential velocity is very small without obvious secondary flow.

(5) When the intake duct is combined with a mixed-flow waterjet pump at various navigation speeds, the nonuniformity of the optimized intake duct decreases by $20.4 \%$ and the perpendicularity increases by $4.11 \%$ on average. The results indicate that the outflow quality is improved after optimization. However, the non-uniform inflow provided by different intake duct has little impact on the waterjet pump, but mainly affects pressure distribution on suction surfaces of impeller blade and causes different shaft power.

\section{Acknowledgment}

This work was financially supported by the National Natural Science Foundation of China (Grant Nos 51776102 and 11772340), Science and Technology on Water Jet Propulsion Laboratory (Project No. 61422230103162223004) and State Key Laboratory of Hydroscience and Engineering (Project No. sklhse-2017-E-02).

\section{Nomenclature}

CFD Computational Fluid Dynamics

RANS Reynolds-averaged Navier-Stokes

IVR Inlet Velocity Ratio, IVR $=V_{\mathrm{p}} / V_{\mathrm{s}}$

DOE Design of Experiments

NSGA-II Non-Dominated Sorting Genetic Algorithm-II
TOPSIS Technique for Ordering Preferences by Similarity to Ideal Solution

PF Pareto Front

BCS Best Compromise Solution

D Diameter

$L_{\text {duct }} \quad$ Total length of intake duct

$H_{\text {duct }} \quad$ Mounting height of intake duct

$L_{1} \quad$ Length of the horizontal straight section

$R_{1} \quad$ Radius on the upper side of the elbow section

$L_{2} \quad$ Length on the upper side of the inclined straight section

$R_{2} \quad$ Radius on the upper side of the ramp section

$L_{3} \quad$ Length on the lower side of the inclined straight section

$R_{3}, R_{4} \quad$ Lip radius on the upper and lower side, respectively

$h_{\text {lip }} \quad$ Lip vertical distance from the center of the upper arc to the hull

$L_{0} \quad$ Inflow length

$\alpha_{\text {duct }} \quad$ The inclination angle between the duct axis and the hull

$\eta_{\text {duct }} \quad$ Hydraulic efficiency

$\xi \quad$ Outflow nonuniformity

$\phi_{\mathrm{p}} \quad$ Outflow perpendicularity

$E_{\text {in }} \quad$ Total energy at the inlet plane positioned one impeller diameter forward of the ramp tangent point

$E_{\text {out }} \quad$ Total energy at the outlet plane of intake duct

$\rho \quad$ Fluid density

$V_{\text {in }}, V_{\text {out }}$ Velocity at the inlet plane and outlet plane of intake duct, respectively

$p_{\text {in }}, p_{\text {out }} \quad$ Static pressure at the inlet plane and outlet plane of intake duct, respectively

$p_{\mathrm{r}} \quad$ Reference pressure

$V_{\mathrm{a}}, V_{\mathrm{t}} \quad$ Axial velocity and tangential velocity at the outlet plane of intake duct, respectively

$V_{\mathrm{wt}} \quad$ Local velocity at the inlet plane of the water tank with a distance of $y_{\text {rel }}$ from the hull

$V_{\mathrm{s}} \quad$ Ship navigation speed

$\delta \quad$ Thickness of the hull boundary layer

$L_{\text {in }} \quad$ Distance from the domain inlet plane to the inlet of intake duct, $L_{\text {in }}=25 D$

Re Reynolds number, $R e=V_{\mathrm{s}} L_{\mathrm{in}} / v$

$v \quad$ Fluid kinematic viscosity

$V_{\mathrm{p}} \quad$ Averaged outflow velocity of the outlet pipe 


\section{References}

Allison, J., 1993. Marine Waterjet Propulsion. Waterjet Propelled Craft.

Bulten, N., 1999. Influence of boundary layer ingestion on waterjet performance parameters at high ship speeds. In: Proceedings of the 5th International Conference on Fast Sea Transportation, pp. 883-892.

Bulten, N.W.H., 2006. Numerical Analysis of a Waterjet Propulsion System.

Cao, P., Wang, Y., Kang, C., Li, G., Zhang, X., 2017. Investigation of the role of nonuniform suction flow in the performance of water-jet pump. Ocean. Eng. 140, 258-269.

Chang, S., Wang, Y., Pang, Z., Ding, J., 2010. Research on effects of IVR conditions in waterjet inlet performance. J. Wuhan Univ. Technol. (Transp. Sci. Eng.) 34 (04), $721-724+729$.

Ding, J., Wang, Y., 2011. Research on the parametric design of an inlet duct found in a marine waterjet. J. Harbin Eng. Univ. 32 (04), 423-427.

Duerr, P., von Ellenrieder, K., Ieee, 2013. Investigation of Non-uniform Waterjet Pump Inflow for a Range of Ship Speeds, 2013 Oceans - San Diego. Ieee, New York.

Duerr, P., von Ellenrieder, K.D., 2015. Scaling and numerical analysis of nonuniform waterjet pump inflows. IEEE J. Ocean. Eng. 40 (3), 701-709.

Griffith-Jones, G.J., 1994. Investigation of Incompressible Flow through an Intake Duct with Applications to Waterjet Propulsion. Mechanical Engineering. University of Canterbury.

Huang, R.F., Luo, X.W., Ji, B., Wang, P., Yu, A., Zhai, Z.H., Zhou, J.J., 2015. Multiobjective optimization of a mixed-flow pump impeller using modified NSGA-II algorithm. Sci. China Technol. Sci. 58 (12), 2122-2130.

Ji, G., Cai, Y., Li, N., Yin, X., Yu, y., 2016. Analysis about effect of inclination angle on the efficiency of the waterjet propulsion inlet duct. Ship.Sci. Technol. 38 (5), 55-58.

Ji, G., Cai, Y., Li, N., Yu, Y., 2016. Influence of lip parameters on non-uniformity and stagnation point at inlet duct of waterjet propulsion. Shipbuild.China. 57 (4), 109-115.

Jung, K.H., Kim, K.C., Sang, Y.Y., Kwon, S.H., Chun, H.H., Kim, M.C., 2006. Investigation of turbulent flows in a waterjet intake duct using stereoscopic PIV measurements. J. Mar. Sci. Technol. 11 (4), 270-278.

$\mathrm{Li}, \mathrm{X} ., 2008$. Study of multi-objective optimization and multi-attribute decision making of economic load dispatch problem. Proc.CSEE. 28 (35), 102-107.

Li, X., 2009. Study of multi-objective optimization and multi-attribute decision-making for dynamic economic emission dispatch. Electr. Mach. Power Syst. 37 (10), $1133-1148$.
Liu, C.J.A., Wang, Y.S.A., Zhang, Z.H.B., Liu, J.B., 2010. Research on effect of different flow control volume on waterjet performance prediction. J. Ship Mech. 14 (10), 1117-1121.

Liu, R., Huang, G., 2011. Numerical study on effect of inlet lip on hydrodynamics for waterjet propulsion. Shipbuild.China. 52 (01), 39-45.

Lu, G., Zuo, Z., Liu, D., Liu, S., 2019. Energy balance and local unsteady loss analysis of flows in a low specific speed model pump-turbine in the positive slope region on the pump performance curve. Energies 12 (10), 1829.

Luo, C., Cheng, L., Liu, C., 2015. Numerical simulation on the performance of waterjet propulsion system with the protecting grid for different setting angles. J. Yangzhou Univ. Nat. Sci. Ed. 18 (02), 65-69.

Lv, H., 2014. High-speed Mixed-Flow Pump Inlet Duct Optimization and the Research of Propulsion Performance. Jiangsu University of Science and Technology, Zhenjiang.

Park, W.-G., Yun, H.S., Chun, H.H., Kim, M.C., 2005. Numerical flow simulation of flush type intake duct of waterjet. Ocean. Eng. 32 (17-18), 2107-2120.

Park, W.G., Jang, J.H., Chun, H.H., Kim, M.C., 2005. Numerical flow and performance analysis of waterjet propulsion system. Ocean. Eng. 32 (14-15), 1740-1761.

Park, W.G., Yun, H.S., Chun, H.H., Kim, M.C., 2005. Numerical flow simulation of flush type intake duct of waterjet. Ocean. Eng. 32 (17-18), 2107-2120.

Roberts, J.L., 1998. The Influence of Hull Boundary Layers on Waterjet Intake Performance. University of Tasmania.

Terwisga, T., van, 1991. The Effect of Waterjet-Hull Interaction on Thrust and Propulsive Efficiency. Waterjet Propelled Craft.

Van Esch, B.P.M., 2009. Performance and radial loading of a mixed-flow pump under non-uniform suction flow. J. Fluids Eng.Trans. ASME 131 (5), 0511011-0511017.

Verbeek, R.N.W.H.B., 1998. Recent Development in Waterjet Design, International Conference on Waterjet Propulsion II. RINA, Amsterdam, Netherlands.

Wang, S., Wang, Y., Jin, S., Ding, J., 2013. Effect of inlet grid on duct flow performance and waterjet propulsion performance. J. Mech. Eng. 49 (14), 164-169.

Wilhelm, S., Balarac, G., Metais, O., Ségoufin, C., 2016. Analysis of head losses in a turbine draft tube by means of 3D unsteady simulations. Flow, Turbul. Combust. 97 (4), 1255-1280.

Young, Y., Savander, B., Kramer, M., 2011. Numerical Investigation of the Impact of SESWaterjet Interactions and Flow Non-uniformity on Pump Performance, 11th International Conference on Fast Sea Transportation. FAST. 